University of Rhode Island

DigitalCommons@URI

Open Access Dissertations

1986

\title{
A Comparison of Several Component Matching Indices: A Simulation Study
}

Edward Guadagnoli

University of Rhode Island

Follow this and additional works at: https://digitalcommons.uri.edu/oa_diss

\section{Recommended Citation}

Guadagnoli, Edward, "A Comparison of Several Component Matching Indices: A Simulation Study" (1986). Open Access Dissertations. Paper 935.

https://digitalcommons.uri.edu/oa_diss/935

This Dissertation is brought to you for free and open access by DigitalCommons@URI. It has been accepted for inclusion in Open Access Dissertations by an authorized administrator of DigitalCommons@URI. For more information, please contact digitalcommons-group@uri.edu. 
A COMPARISON OF SEVERAL COMPONENT MATCHING INDICES :

A SIMULATION STUDY

BY

EDWARD GUADAGNOLI

A Dissertation SUBMItTED IN PARTIAL FULFILLMENT OF TBE REQUIREMENTS FOR THE DEGREE OF

DOCTOR OF PHILOSOPHY

IN

PSYCHOLOGY

UNIVERSITY OF RHODE ISLAND

1986 
Abstract

Researchers who employ multivariate techniques often wish to compare solutions obtained from two independent studies. When factor analysis or component analysis procedures are employed, pattern matrices are compared. In the present study, the matching performance of several component matching indices, coefficient of congruence (c), s - statistic $(\mathrm{s})$, Pearson $r(r)$, and kappa $(k)$, were compared under a variety of experimental conditions. Independent variables manipulated were (1) component saturation or size of component loadings, (2) sample size, the number of variablea, and (4) the number of components. Five sample component patterns were computer generated and matched, employing each index, to their population component pattern. Matching performance was assessed both witbin indices and between indices. No index was free of the influence of the variables manipulated. Component saturation and sample size exerted the primary influence on index matching performance. An increase in either of these variables resulted in index values that wore accurately reflected whether or not components matched. With the exception of $r$, Iittle difference in matching performance between indices was observed. For all practical purposes, matching performance for $c, s$, and $k$ was indigtinguishable when both corresponding components and non-corresponding components were compared. 
Table of Contents

ABSTRACT

Pattern Matrix Comparison

Comparison of Index Performance 10

Purpose of Study

METHOD

Factor Matching Indices

Factors Manipulated

17

Data Generation

18

Component Matcbing

RESULTS

Matching Performance Within Indices 24

Matching Performance Between Indices

DIS CUS S ION

48

REFEREACES

APPENDIX A

61 


\section{List of Tables}

TABLE

PAGE

1 Tabulation Table Required to Calculate the statistic

2 Decision Table Comparing Decisions on Salience Between Factors 9

3 Overa11 Design

4 Population Pattern Matrix (A) for $p=12 ; m=3 ; a_{i j}=.60$ 20

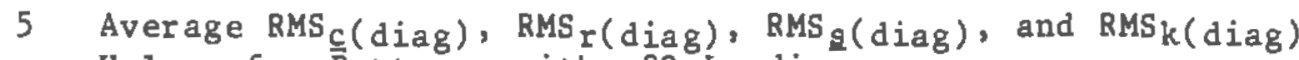

Values for Patterns with .80 Loadings

6 Average $\operatorname{RMS}_{\mathrm{C}}(\mathrm{diag}), \mathrm{RMS}_{\mathrm{r}}$ (diag), $\mathrm{RMS}_{\mathrm{g}}\left(\mathrm{diag}_{\mathrm{g}}\right)$, and $\mathrm{RMS} \mathrm{k}(\mathrm{diag})$

Values for Patterns with .60 Loadings

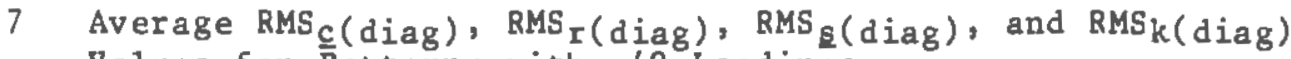

Values for Patterns with .40 Loadings

8 Average $R M S_{\mathcal{C}}($ off $), \operatorname{RMS}_{\mathrm{r}}($ off $), \operatorname{RMS}_{\mathrm{g}}(\mathrm{off})$, and $R M S_{K}$ (off)

Values for Patterns with .80 Loadings

9 Average RMS $\left(\right.$ off), $\operatorname{RMS}_{\mathrm{r}}$ (off), $R M S_{\mathrm{g}}$ (off), and $R M S_{k}$ (off)

Values for Patterns with .60 Loadings

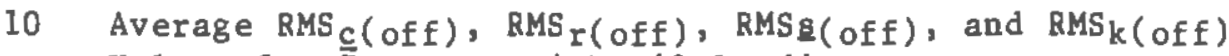

Values for Patterns with .40 Loadings

11 Multiple Regression Results from Prediction of RMSi(diag)

Using the Simple ModeI

12 Multiple Regression Regults from Prediction of RMSi(off)

Using the Simple Model

13 Correlation Matrix of RMSi(diag) Values

14 Correlation Matrix of RMS ( off) Values 


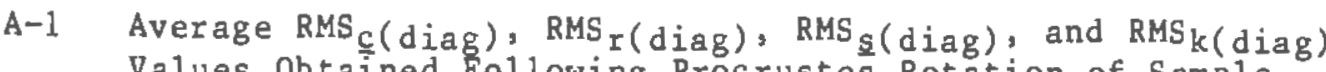

Values Obtained Following Procrustes Rotation of Sample

Pattern for Patterns with .80 Loadings

A-2 Average RMS (diag), RMS $_{\mathrm{I}}$ (diag), RMS $\mathrm{d}_{\mathrm{g}}$ (diag), and RMS $k$ (diag)

Values Obtained Following Procrustes Rotation of Sample

Pattern for Patterns with .60 Loadings

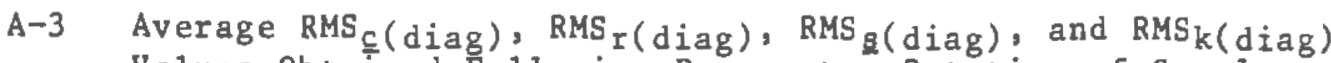

Values Obtained Following Procrustes Rotation of Sample

Pattern for Patterng with .40 Loadings

A-4 Average RMS $\mathrm{C}($ off $), \mathrm{RMS}_{\mathrm{r}}$ (off), RMS $_{\mathrm{g}}$ (off), and $\mathrm{RMS}_{\mathrm{k}}$ (off)

Values Obtained Following Procrustes Rotation of Sample

Pattern for Patterng with. 80 Loadings

A-5 Average RMS $($ of $f$ ), RMS $r$ (off), RMS $g$ (off), and RMS $k$ (off)

Values Obtained Following Procrustes Rotation of Sample

Pattern for Patterns with .60 Loadings

A-6 Average RMS $\left(\right.$ off), RMS $r(o f f), R M S_{g}$ (off), and $R M S_{k}$ (off)

Values obtained Following Procrustes Rotation of Sample

Pattern for Patterns with .40 Loadings 
List of Figures

F IGURE

PAGE

1 Average RMS $i$ (diag) Across All Levels of $a_{i j}, P$, and $m$

2 Average RMS $i$ (off) Across All Levels of $a_{i j}, p$, and m 
Introduction

Researchers who employ multivariate techniques often wish to compare solutions obtained from two independent studies. Relevant information from each solution is usually contained within a $p x m(p)$ m) rectangular matrix. Examples of such matrices include canonical correlation's structure matrix, discriminant analysio" standardized weight matrix, and factor analysis" or component analysis" pattern matrix. The similarity between solutions may be assessed in several ways. An overall assessment of the similarity between matrices may be performed. In this case, a single scalar value is calculated which provides a global indication of the degree of congruence between solutions. Comparison of matrices may also occur at either the vector or matrix element level. In these instances, multiple indicators of congruence are generated.

The most common matching situation for researchers who employ factor analysis or component analysis techniques is comparison of pattern matrices which result when the same variables are administered to different samples of individuals. This situation provided the focus for the present study. This matching situation can be partitioned into designs which assess factorial replication and designs which assess factorial invariance (Derogatis, Serio, and Cleary, 1972). Factorial 
replication designs are employed to assess similarity of solutions derived from random samples of individuals obtained from the same population. Replication between samples obtained when a population parameter (sex, age, race, SES, etc.) has been varied is assessed in factorial invariance designs. Alternative matching situations may involve the comparison of solutions derived from the same individuals but different variables; the same individuals and variables when different factor analysis techniques are employed; and different variables and different individuals.

The purpose of the present study was to evaluate the performance of four factor matching indices, the coefficient of congruence (Burt, 1948; Tucker, 1951; Wrigley and Neuhaus, 1955), the Pearson product moment coefficient of correlation, the s-statistic (Cattel1, 1949; Cattel1 \& Baggaley, 1960; Cattell Balcar, Horn, \& Neselroade, 1969), and kappa (Cohen, 1960). Index performance was assessed witbin the framework of principal component analysis (Hotelling, 1933) through comparison of component patterns.

Advantages and disadvantages of each index have been identified. A lack of consensus exists, therefore, as to the proper index to employ under tbese conditions. The performance of these indices was evaluated in order to select the index which most accurately identified components known to both match and not match under a variety of experimental conditions. Index performance was evaluated following manipulation of sample size, component saturation or size of component loadings, number of variables, and number of components. The influence of these variables was evaluated both between indices and within indices. 
Both other forms of matrices and other matching techniques may be employed to compare factor analysis or component analysis solutions. Nunnally (1978) suggested that factor or component scores be employed when comparing different solutions. However, since comparisons are often made between solutions obtained from different researchers (e. $g$. comparison of a literature reported solution with a solution obtained from one's own data) factor score comparison procedures were not assessed in the present study. Information required to calculate these indices ( $e$. $g$. the $R$ matrix) is generally not available to the researcher when comparison is made across studies. Factor pattern comparison was thought to be of greater interest and utility.

A different technique employed to assess factor similarity is the confirmatory maximum likelihood method (Joreskog, 1969). This approach is suggested, however, when a well defined theory with a highly specific structure is tested across solutions (Korth and Tucker, 1975, Gorsuch, 1983). Ten Berge (1986) has argued that the confirmatory maximum likelihood method's technical problems, conceptual criticisms, and inability to identify where factors vary across populations make the technique of 1 imited use to the practitioner. For these reasons, he has suggested that descriptive indices should not yet be ignored.

Prior to discussion of the specific matching indices employed in this study, it is emphasized that assessing the similarity of independently derived solutions is the focus of this research. When solutions are brought to maximum congruence (e. g. Tucker, 1951; Ahmavaara, 1954; Meredith, 1964, Baltes, Eyferth, \& Schaie, 1969; Nesselroade \& Baltes; 1970, Kaiser, Hunka, \& Bianchini, 1971; Korth \& 
Tucker, 1975) or when one solution is rotated to match the structure of the other by Procrustes rotation, "the principles of evaluation of goodness of mutual fit is more complex and difficult" (Cattel1, 1978, p. 251). Given the lack of consensus as to the appropriate factor or component matching approach, such matters of complexity are better left to future research. It is also true that situations exist (e. $g$. in the evaluation of test bias) where independently derived solutions are the only practical sources of comparison (Reynolds Harding, 1983).

\section{Patkerg Matrix Comparison}

The coefficient of comgruence (s). This index, attributed to several researchers (Burt, 1948; Tucker, 1951; Wrigley and Newhouse, 1955), is a measure of proportional similarity between two vectors of factor or component loadings. Computational simplicity and intuitive appeal have led to its extengive use by researchers. This measure is defined as:

$$
\text { (c) }(\underset{\sim}{a, b})=\cos (\underset{\sim}{a}, b)=a^{\prime} b\left(a^{\prime} a b^{\prime} b\right)^{-1 / 2}
$$

where $\mathbf{a}$ and $b$ represent individual factor or component loading vectors. Values of $c$ can range between -1.00 and +1.00 witb $s=0.00$ representing a total lack of agreement. Regearchers have suggested that values greater than .90 (Cureton and D'Agostino, 1983; Mulaik, 1972) or .80 (Tucker, 1951) be employed to identify congruent factors. A maximum value of .30 should result when factors expected to be non-congruent are 
matched (Andresen, Stemmler, Thow, and Irrganz, 1984). The coefficient of congruence is not a correlation coefficient since values used to compute the statistic are not deviates from their corresponding means. Cohen's (1969) general coefficient of relationship, $r_{g}$, equals $c$ when deviations from zero are employed. Sjoberg and Holley's (1967) H and the coefficient of proportionality (Zegers \& Len Berge, 1985), Pij, are also identical to $\subseteq$.

While c enjoys popularity, several criticisms have been leveled against it. A common problem is spuriously bigh values which result when factors containing variables with the same sign and a bigh proportion of salient loadings are compared (Pinneau \& Newhouse, 1964; Derogatis, Serio, \& Cleary, 1972). This result will occur whether or not the pattern of loadings on each factor is similar. Another problem relates to the fact that an adequate test of significance has not been developed for $\subseteq$. Korth and Tucker (1975), using simulated data, bave explored the distribution of $c$ when matching "chance" factor patterns. Their results are of limited use, however, because factor patterns compared were transformed to a common space and only a limited number of pattern characteristics were examined. Cattell (1978) noted that an attempt to investigate the distributions of $\subseteq$ using actual data has also yielded limited results. Despite its drawbacks, c remains a popular factor matching index.

The Pearson product = moment coefficient of correlation (r). Calculation of I between factor or component loadings has been suggested as another matching technique. A minimum correlation of $x=.75$ is suggested to imply factors of similar interpretation (Cliff, 1966). 
This method suffers from two defects. In calculating $r$, information regarding the sign of a particular logding may be lost. Since deviations are calculated from the mean of each column of loadings, the presence of high loadings within a colum may influence the mean such that low positive loadings will have negative deviations. The resulting deviations will, therefore, not reflect the actual pattern of factor loadings (Cattel1, 1978). In addition, $r$ is influenced by the rank order of factor loodings. If the rank order of loadings for two factors is identical, the resulting I will not vary as a result of differences in the magnitude of loodings between factors (Cattel1, 1978). Cohen's (1969) $I_{g}$ equals $r$ when deviates are calculated from the mean. Zegers and ten Berge's (1985) coefficient of linearity is also identical to $r$. The $\mathrm{s}$ = statistic. Cattell, over several phases (Cattel1, 1949; Cattell \& Baggaley, 1960; Catte11, Balcar, Horn, \& Nesselroade, 1969) developed a non-parametric index (s) based on the presence of galient and non-salient (hyperplane) variables. The s index provides a test as to whether the number of salient loadings common between two factors or componente could have occurred by cbance. To calculate this index, the match between two factors or components must be assessed with respect to positive salients (PSS), negative salients (NS), and hyperplane ( $B$ ) variables. A tabulation table (Table 1) is constructed to calculate this index. The 6 index is then calculated as

$$
\mathrm{g}=\frac{\mathrm{f}_{11}+\mathrm{f}_{33}-\mathrm{f}_{13}-\mathrm{f}_{31}}{\mathrm{f}_{11}+\mathrm{f}_{33}+\mathrm{f}_{13}+\mathrm{f}_{31}+1 / 2\left(\mathrm{f}_{12}+\mathrm{f}_{21}+\mathrm{f}_{23}+\mathrm{f}_{32}\right)}
$$


Table 1

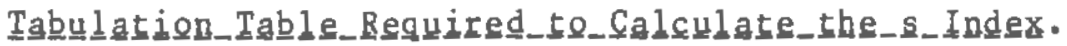

Factor 2

\begin{tabular}{|c|c|c|c|c|}
\hline Factor 1 & PS & $\mathrm{H}$ & NS & \\
\hline PS & $\mathrm{f}_{11}$ & $\mathrm{f}_{12}$ & $f_{13}$ & $\mathrm{n}_{1}$ \\
\hline $\mathrm{H}$ & $\mathrm{f}_{21}$ & $\mathrm{f}_{22}$ & $\mathrm{f}_{23}$ & $\mathrm{n}_{2}$ \\
\hline \multirow[t]{2}{*}{ NS } & $f_{31}$ & $f_{32}$ & $f_{33}$ & $n_{3}$ \\
\hline & n.1 & $\mathrm{n} .2$ & $\mathrm{n} .3$ & $\pi$ \\
\hline
\end{tabular}

Note. From The scientific uge of factor analygis in behayioral and life scienges ( $p$ 257) by R. B. Catte11, 1978, New York: Plenum Press. 
where $f_{i j}$ represents the joint frequency of PS, NS, and $B$ variables between factors.

Values of $s$ range from +1.00 (perfect agreement) to -1.00 (complete reflection) with 0.00 representing chance agreement between the two factors. Tables of significance (Cattel1, 1978) based upon the number of variables in common and the percentage of variables present in the byperplane have been developed.

This index is not without its problems. Disagreement exists as to the appropriate cutoff value required to indicate a salient loading. This is a common problem when interpreting factor or component patterns in general. The value chosen is arbitrary and subjective. Cattell (1978) suggested a value of \pm .10 . This value is considered too low by many of today"s researchers. A value of \pm .30 to \pm .40 , more indicative of that actually employed hy applied researchers, has been suggested (Velicer, Peacock, \& Jackson, 1982).

The test of significance for the o statistic bas also been questioned. Probability values offered are estimated and apply to only a limited number of pattern situations (Derogatis et al., 1972). Cattel ( 1984 ) has stated that in bis experience a is a more reliable index of factor matching than $c$. He feels, however, that the "computational convenience" of $c$ has lead to its wider use.

Kages. Another method similar to that of the s statistic employs a 2 × 2 decision table (Table 2) created following a comparison of salient and non - salient loadings present in two factors or components of different solutions. This method also requires first deciding upon a cutoff value above which variables are determined to be salient. 
Table 2

Deccision_Table_Comparing_Decigions_on_Salience_Between_Factors

Factor 2

YES

No

Factor 1

YES

No Error: A

Error

NO

Error

No Error: B 
Variables are considered salient to a factor if they exceed the cutoff value witbout regard to sign. A great variety of agreement statistics (Fleisg, 1981) may be calculated from the type of decision table described in Table 2. The kappa (k) statistic (Cohen, 1960), a measure of agreement, is advocated because it provides a correction for chance expected agreement. Complete agreement between two factors is defined by a $k$ of 1.00 . $K>0.00$ signifies agreement greater than or equal to the chance level, values below 0.00 represent agreement below the chance level. Landis and Roch (1977) provide guidelines for interpreting k. Values of $k$ greater than .75 represent excellent agreement, valueg between .40 and .75 are indicators of fair to good agreement and values below .40 represent poor agreement. Cohen (1969) suggested that k less than zero is of acadenic rather than practical interest.

\section{Comparigon of Index Performance}

Several researchers have empirically compared different approaches which asgess factor similarity. Derogatis, et al. (1972) compared results obtained when $f, r I V$ (a factor or component score (coefficient) method), and s were applied to real data sets representing several factor matching situations. Fixed variables and subjects - different rotational procedure, factorial replication, and factorial invariance situations were examined. Principal component analysis (PCA) was employed as the factor extraction technique. For all indices, the transition from the rotational situation to the invariance situation demonstrated a decrease in the comparability between factors expected to 
replicate. In all situations, the matrix of $r I V$ coefficients contained high diagonal values (comparison of corresponding components) and low off-diagonal coefficients (comparison of non-corresponding components). Congruence coefficients were high for both diagonal and off-diagonal coefficients. Significant a statistic values resulted for both diagonal and off-diagonal values. The frequency of significant statistics varied as a function of the hyperplane boundary selected. The more liberal hyperplane boundary (.35 as opposed to .25) yielded fewer significant off-diagonal coefficients. Derogatis, et al. (1972) concluded that all three indices possessed validity, however, all (particularly $s$ and $s$ ) also possessed limitations. The three measures, therefore, "cannot be judged in absolute terms" (Derogatis, et a1., 1972, P. 791).

Baker (1973) matched matrices generated from sociometric rating data obtained from psychiatric patients. The Pearson I coefficient, $\underline{c}$, s, and Nunnally's (1967) factor score matching method were employed to measure factor similarity. Five samples of patients ranging from $N=60$ to $N=306$ were selected and a PCA solution obtained for each. Orthogonal rotation and two types of oblique rotation were performed. For each type of rotation, solutions were compared two at a time. Nunnally's (1967) procedure was employed only in a reduced set of comparisons. In addition to examining indices obtained from each comparison, Baker (1973) also correlated the results obtained from each matching procedure (i. e, Pearson $r$ with $\varepsilon$, Pearson $r$ with s, etc.). Direct examination of each index's performance and asgessment of correlations obtained between indices indicated that Pearson I and $\underline{c}$ 
performance were similar (particularly for orthogonal solutions). Both indices, however, sometimes resulted in ambiguous conclusions with respect to comparison of factors not expected to match. Baker (1973) concluded that "only the S-index provided an unambiguous, statistical test of the hypothesis of the equality or match of factors." This conclusion, however, appears to be based primarily on the argument that probability values are available to assess the statistic. The limitations associated with these published probability values have been discussed earlier.

Reynolds and Harding (1983) employed six methods to compare (1) solutions obtained from black and white samples on the WISC-R and (2) solutions obtained from males and females on the Revised-Children's Manifest Anxiety Scale (RCMAS). The six indices employed were $\underline{c}$ determined from factor solutions obtained from a correlation matrix, $\underline{c}$ determined from factor solutions obtained from a covariance matrix, Pearson $\mathbf{r}$ between factor loadings, Pearson $r$ between Fisher-transformed factor loadings, $s$, and Pearson $r$ between factor scores determined from the pooled solution with scores obtained separately for each solution. A principal factor method with varimax rotation was employed in each analysis. Comparable results were obtained across indices for each analysis. Reynolds and Harding (1983) stated that "conclusions would have remained constant in each study regardless of the index employed." (p. 723). Results were presented, however, only for comparison of factors expected to be similar (the diagonal of each index matrix). Without examination of the off-diagonal values for each index, a proper evaluation of matching performance cannot be made. 
Past research has failed to identify an index which provides unambiguous results when factors from two independent solutions are compared. Generally, researchers reported that the quality of the match between solutions would be consistent whatever the index employed. This was the case even when previously reported problems associated with various indices (e.g. high off-diagonal values for c; variability in $s$ with respect to hyperplane cutoff selection) arose in the empirical evaluation of these measures. Previous research is also limited in scope. Investigations were generally performed on one data set, thereby Iimiting study to the influence of one value of $p$ (number of variables), m (number of factors), and $N$.

\section{Puyrpoge of Study}

The purpose of the present study was to assess the performance of several component matching indices ( $, g, g, r$ and $k$ ) when sample component patterns were matched to population component patterns. Component score or component coefficient methods, such as IV, were not evaluated because information required to calculate these indices is generally not available when comparisons are made across studies. Matching performance both within and between indices was assessed. of the indices chosen for evaluation, $s, s$, and $r$ are commonly accepted as the more popular matching indices. Kappa was included as a less computationally complex alternative to Q. Employing simulated data, a broader range of conditions than those examined in past research were assessed. The use of simulated data allowed direct control of variables manipulated and comparison to known solutions was possible. 
Index performance was assessed as a function of the manipulation of four variables: (1) component saturation $\left(a_{i j}\right)$ or the size of component loadings. Guadagnoli and Velicer (1986) have shown that this variable exerted the most important influence on overall component pattern stability. It was expected that the performance of all indices would be influenced by this variable. Greater component saturation was expected to result in more accurate index performance. (2) Sample size. Secondary to $a_{i j}$, increased $N$ has been shown to positively influence component pattern stability (Guadagnoli \& Velicer, 1986). The accuracy of index performance was expected to increase with increased N. (3) The number of variables ( $p$ ) and (4) the number of components (m). While these values have been observed to play a minor role in Qyerall component pattern stability (Guadagnoli \& Velicer, 1986), one or both of these factors (e. $g$. in combination as $\mathrm{p} / \mathrm{m}$ ) may influence matching at the component level. With respect to individual index performance, the magnitude of $s$, when non-corresponding components were matched, was also of interest since this index has been criticized as producing high values in this type of matching situation. Also, since $k$ was offered as a less computationaly complex alternative to $\underline{s}$, it was expected that matching performance would not differ greatly between these indices.

While the influence of the factors manipulated can be predicted from past research, it was expected that, under the matching situations employed, the index which displayed the most accurate performance would be influenced least (relative to the other indices) by these factors. That is, while the performance of each index may be influenced by the factors manipulated, the influence should be differential if in fact one index is superior to the others. 
Method

In order to assess performance of the factor matching indices selected, several variables were manipulated. Population and sample component solutions were generated as a function of various levels of $p$, $m, N$, and $a_{i j}$. An attempt was made to sample conditions which are similar to those of ten encountered by applied researchers. The situations generated, however, were typically simpler than real-world conditions. Population component patterns included variables wbich loaded on only one component. Each component was defined by an equal number of variables. All non-zero loadings were equal. These conditions may be perceived as representing relatively "clean" or idealized solutions, however, this study represented a necessary first step in the evaluation of this problem.

A principal component procedure (Hotelling, 1933) was employed to produce population and sample component patterns from computer-generated correlation matrices. Although factor analysis procedures are commonly recommended, Velicer (1974, 1976, 1977) and Velicer et al. (1982) demonstrated that principal component solutions differ little from solutions generated from factor analysis methods. Additionally, serious theoretical problems exigt with the factor analysis model (steiger and 
Schonemann, 1978). Component analysis does not suffer from some of the convergence problems and computational limitations that factor analysis does, permitting assessment of a wider range of situations (Jackson \& Chan, 1980; Velicer \& Jackson, 1985). Further, Glass and Taylor (1966), following a survey of educational research journals, reported that component analysis was the more frequently performed analysis. Pruzek and Rabinowitz (1981), over a decade later, report that this trend not only has continued but has increased.

Following principal component analysis of computer generated population and sample correlation matrices, sample components were matched to population components employing each of the matching indices indicated above.

\section{Factoㅣ Matchbing Indic토요}

Methods for calculating $c, 8, r$, and $k$ have either been presented previously or are well known. For the calculation of $s$ and $k$, loadings $\geq .30$ were defined as salient. The $\mathbf{8}$ statistic was not evaluated with respect to associated probability values. Instead, factor replication as measured by the s. statistic was "...considered in the same way as reliability, that is, with the aim being to achieve an index approaching unity rather than differing from zero" (Walkey \& McCormick, 1985, P. 65). Evaluation of $\mathrm{s}$ in this way is consistent with the commonly accepted interpretation of $\varepsilon, r$, and $k$ values. 


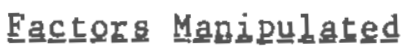

The performance of each index was examined as a function of five levels of $N$, two levels of $P$, three levels of $a_{i j}$, and two levels of $m$. Sample sizes of $N=50,100,150,300$, and 500 were chosen to represent a range of levels which are of ten employed by the applied researcher. Note that $N=50$ was not chosen as a practical lower limit for sample size but as an extremely low value to which solutions derived from larger sample sizes could be evaluated.

Number of variables $(p)$ included $p=36$ and $p=72$. Past research involving pattern comparison (Guadagnoli \& Velicer, 1986) suggested that values of $p$ greater than or equal to 72 yielded results which were relatively homogeneous.

The levels $m=6$ and $m=9$ were implemented for the number of components factor. Given the p levels employed, these values yield m/p ratios which are realistic relative to applied situations.

Three levels of $a_{i j}$ were utilized. As noted above, component loadings of .30 or .40 are usually regarded as salient to a particular component while loadings below the cutoff are ignored. Loadings selected for this degign represented the range from close to the lower $\operatorname{limit}\left(a_{i j}=.40\right)$ to a very well defined value $\left(a_{i j}=.80\right)$ above which loadings are usually not found. A value within the moderate range ( $a_{i j}$ $=.60)$ was also included. 


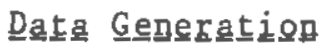

The conditions described above represent $60(5 \times 2 \times 2 \times 3)$ possible conditions $f$ or the generation of correlation matrices. of these, however, only 54 combinations were examined given the $N>P$ condition necessary to perform a principal component analysis. Table 3 provides a description of the overall design.

Population correlation matrices were generated following a procedure previously employed by Guadagnoli and Velicer (1986) and Zwick and Velicer (1982; 1986). A p x m population pattern matrix (A) was generated with respect to every possible $p$, m, and $a_{i j}$ combination defined in the design. Post multiplying $\underset{\sim}{A}$ by its transpose (Á) generated a $p$ X p matrix, $\mathbb{R}^{*}\left(A^{\prime}=\mathbb{R}^{*}\right)$. The population correlation matrix (R) was obtained by replacing the elements in the diagonal of $\mathbb{B}^{*}$ with unities. Table 4 presents an example of $A$ for the case in which $P$ $=12, m=3$, and $a_{i j}=.60$. A computer program developed by Montaneli (1975), based on a method suggested by Odell and Feiveson (1966), was used to generate five ${ }^{l}$ sample correlation matrices from each $\mathbb{R}$ for every level of $N$ employed in the study. Principal component analysis was performed to obtain population and sample component patterns from their respective correlation matrices.

\section{Cogponent Mataching}

The four indices of interest were applied to each individual 
Table 3

Qverall_Degign

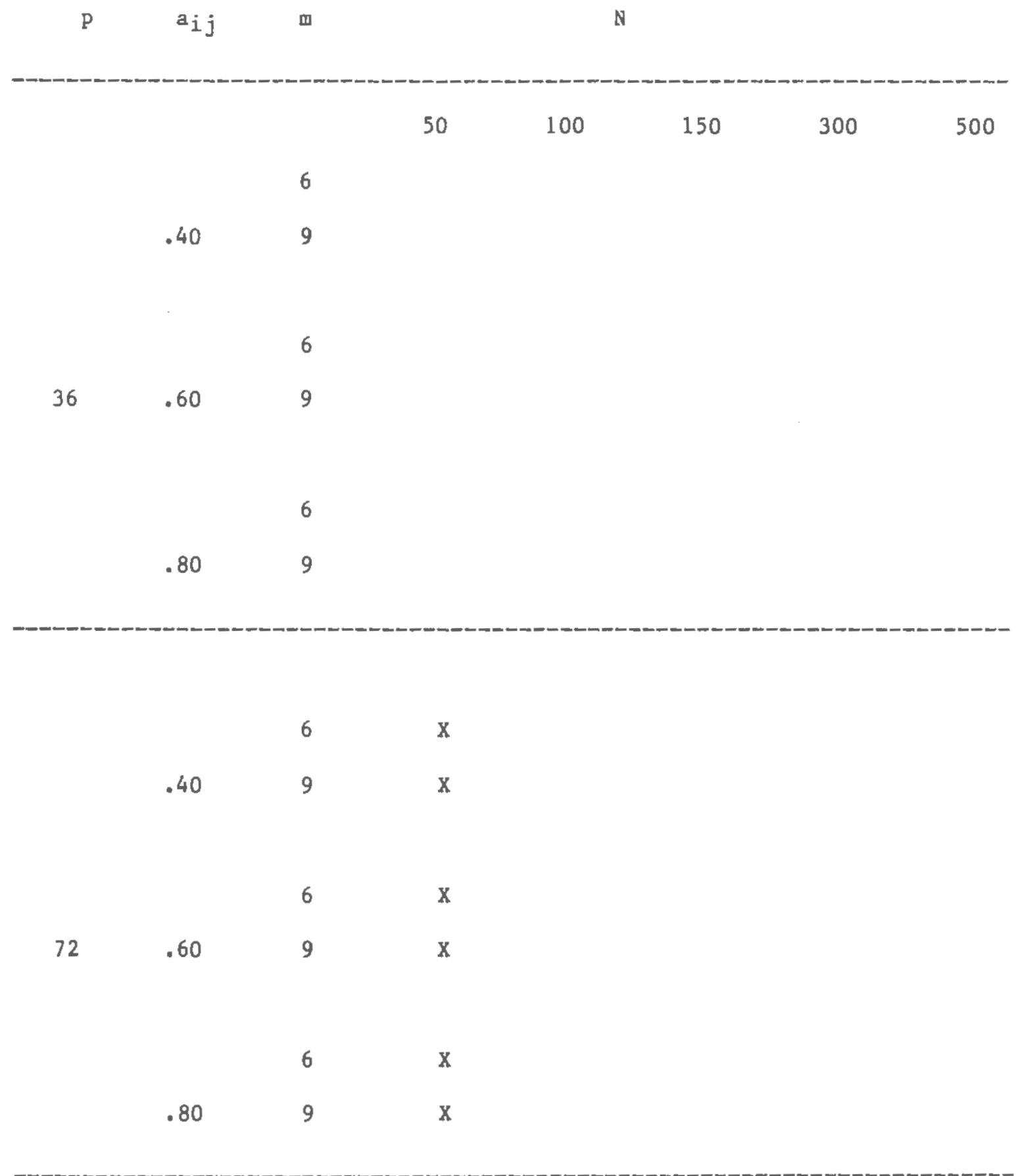

Notes. $X$ indicates cell not examined: $P>N$. 
Table 4

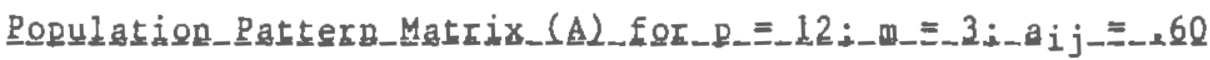

m

$\begin{array}{cccc}1 & 1 & 2 & 3 \\ 2 & 0.60 & 0.00 & 0.00 \\ 3 & 0.60 & 0.00 & 0.00 \\ 4 & 0.60 & 0.00 & 0.00 \\ 5 & 0.60 & 0.00 & 0.00 \\ 6 & 0.00 & 0.60 & 0.00 \\ 7 & 0.00 & 0.60 & 0.00 \\ 8 & 0.00 & 0.60 & 0.00 \\ 9 & 0.00 & 0.60 & 0.00 \\ 10 & 0.00 & 0.00 & 0.60 \\ 11 & 0.00 & 0.00 & 0.60 \\ 12 & 0.00 & 0.00 & 0.60 \\ & 0.00 & 0.00 & 0.60\end{array}$


population - sample component comparison defined by the above design. Matching followed varimax rotation (Kaiser, 1958) of population and sample patterns. In order to facilitate comparison between components, a permutation matrix (Velicer, 1974, 1976, 1977), $\underset{\sim}{\sim}$, was generated. This matrix allowed a one to one component match to be made with the population pattern by permuting the columns of the sample component pattern. If $\underset{\sim}{\sim}$ did not exist for a particular match, $\underset{\sim}{\sim}$ was defined as $\underset{\sim}{\sim}$ the identity matrix. Matches following orthogonal Procrustes rotation of the sample component pattern were also considered.

For each sample - population comparison, $G_{i}(i=\underline{s}, \underline{s}, r$, and $k)$, an $m x$ matrix, was constructed. This matrix contained index values for each possible population - sample component match.

In order to compare performance between indices, a common statistic, root mean square deviation (RMS; the square root of the average squared deviations between two vectors), was calculated. This statistic was obtained twice, once to represent the quality of performance relative to diagonal values of $\mathrm{G}_{i}$ (comparison of corresponding components) and again to represent the quality of performance relative to off-diagonal values of $G_{i}$ (comparison of

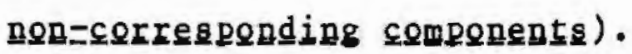

The indices employed in this study have in common that a perfect match between two components is indicated by an index value of 1.00 and total independence between two components is indicated by an index value of 0.00 . By design, sample component patterns were generated as a function of their population component pattern. It was expected, therefore, that $G_{i}$ should equal the identity matrix (I), Whatever the 
index involved, the diagonal elements of $\mathrm{G}_{i}$, representing matches of corresponding components, were expected to equal 1.00. Off diagonal elements of $G_{i}$, indicating the match between non-corresponding components, were expected to equal 0.00 . Resulting $G_{i}$ matrices varied from $\underset{\sim}{\sim}$ as a function of the index's ability to describe the quality of the match between components and as a function of the experimental conditions ( $p, m, a_{i j}$, and $N$ ) manipulated.

The calculation of RMS provided an indication of the average difference between expected ( 1.00 or 0.00 , depending on the matching situation) and observed index values. For each cell in the design, $\operatorname{RMS}_{i(\operatorname{diag})}\left(i=c, s, r\right.$ and $k$ ) and $\operatorname{RMS}_{i}$ (off) were calculated in order to describe each index's performance between expected and observed values of diagonal and off-diagonal elements of $G_{i}$. The possible range of RMS values was 0.00 to 1.00 . A value of 0.00 indicated perfect agreement between the observed index value and the expected index value. This was true whether assessing the quality of match between corresponding components or non-corresponding components.

RMS $_{i}$ (diag), the deviation associated with comparison of corresponding components, was obtained by comparing diagonal values of $G_{i}$ with a vector of unities. $R^{\prime} S_{i}(o f f)$, the deviation associated with comparison of non-corresponding components, was obtained by comparing off-diagonal values of $G_{j}$ with a vector of $0.00 s$. Within each cell of the design, for each set of five population - sample component pattern comparisons, an average $\mathrm{RMS}_{i}\left(\mathrm{diag}\right.$ ) and $\mathrm{RMS}_{i}$ (off) was calculated.

The influence of the variables manipulated on index performance (Matching Performance Within Indices) was assessed through separate 
wultiple regression models with $\mathrm{RMS}_{i}$ (diag) and $\mathrm{RMS}_{i}$ (off) as dependent variables. Matching Performance Between Indices was assessed through examination of plots generated by plotting $\mathrm{RMS}_{i}\left(\mathrm{diag}_{\mathrm{a}}\right.$ ) and $\mathrm{RMS}_{i}(\mathrm{off})$ as a function of the variables manipulated. 
Results

Five sample correlation matrices, generated for every level of $N$, were derived from each of the 12 population correlation matrices defined by the study's design ( $i$. e. defined by a combination of $a_{i j}$, m, and $p$ levels). Following a principal component analysis of population and bample correlation matrices, the degree of similarity between solutions was assessed by calculating c, s, r, and k. For each population sample comparison an m $x$ m matrix, $G_{i}$, containing index values for each individual component match was obtained. Resulting $\mathrm{G}_{i}$ values were compared to expected index values using the RMS deviation statistic.

Tables 5 through 7 display the average $\operatorname{RMS}_{\underline{\subseteq}}\left(d_{i a g}\right), R_{M} S_{g}(d i a g)$, RMS $_{\mathrm{r}}$ (diag), and RMS $_{\mathrm{k}}$ (diag) values obtained for all levels of N, P, and m. Each Table displays these values for a specific level of aij. RMS $_{i}$ (off) values are presented in a similar manner in Tables 8 through 10.

Matching Rerformance Witbin Indicen

Multiple regresion anslysis was employed to assesa the relationship between the factors manipulated $\left(N, P, m, a_{i j}\right)$ and $R M S_{i}$ 
Table 5

Ayerage_RMㅗ을 Patterng_with_+8Q_Logadiggg

36

72

II

m

$\mathrm{RMS}_{i}(\mathrm{diag}) \mathrm{N}$

9

9

6

\begin{tabular}{|c|c|c|c|c|c|}
\hline \multirow[t]{5}{*}{$\subseteq$} & 50 & .0588 & .0473 & * & * \\
\hline & 100 & .0279 & .0201 & .0306 & .0206 \\
\hline & 150 & .0201 & .0123 & .0202 & .0139 \\
\hline & 300 & .0098 & .0067 & .0102 & .0071 \\
\hline & 500 & .0063 & .0040 & .0066 & .0043 \\
\hline \multirow[t]{5}{*}{$\mathbf{r}$} & 50 & .0628 & .0517 & * & * \\
\hline & 100 & .0293 & .0229 & .0331 & .0230 \\
\hline & 150 & .0212 & .0 .141 & .0217 & .0161 \\
\hline & 300 & .0108 & .0076 & .0113 & .0079 \\
\hline & 500 & .0068 & .0046 & .0071 & .0046 \\
\hline
\end{tabular}


Table 5 (continued)

\begin{tabular}{|c|c|c|c|c|c|}
\hline \multirow[b]{4}{*}{ RMS $_{i}(\mathrm{diag})$} & \multirow[b]{4}{*}{ N } & \multicolumn{4}{|c|}{$\mathrm{p}$} \\
\hline & & \multicolumn{2}{|c|}{36} & \multicolumn{2}{|c|}{72} \\
\hline & & \multicolumn{2}{|c|}{ m } & \multicolumn{2}{|c|}{ m } \\
\hline & & 9 & 6 & 9 & 6 \\
\hline \multirow[t]{5}{*}{$\underline{\mathbf{s}}$} & 50 & .0409 & .0381 & * & * \\
\hline & 100 & .0000 & .0000 & .0000 & .0000 \\
\hline & 150 & .0000 & .0000 & .0000 & .0000 \\
\hline & 300 & .0000 & .0000 & .0000 & .0000 \\
\hline & 500 & .0000 & .0000 & .0000 & .0000 \\
\hline \multirow[t]{5}{*}{$\mathbf{k}$} & 50 & .0469 & .0467 & * & * \\
\hline & 100 & .0000 & .0000 & .0000 & .0000 \\
\hline & 150 & .0000 & .0000 & .0000 & .0000 \\
\hline & 300 & .0000 & .0000 & .0000 & .0000 \\
\hline & 500 & .0000 & .0000 & .0000 & .0000 \\
\hline
\end{tabular}


Table 6

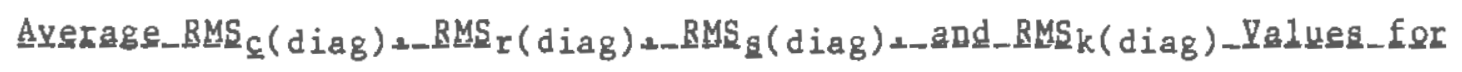
Pattertns_with_e60_Loadings

p

36

72

11

m

RMS $_{i}$ (diag) N

9

6

9

6

\begin{tabular}{|c|c|c|c|c|c|}
\hline \multirow[t]{5}{*}{$\subseteq$} & 50 & .2234 & .1505 & * & * \\
\hline & 100 & .0992 & .0548 & .0925 & .0576 \\
\hline & 150 & .0648 & .0391 & .0601 & .0380 \\
\hline & 300 & .0296 & .0198 & .0303 & .0191 \\
\hline & 500 & .0181 & .0116 & .0181 & .0116 \\
\hline \multirow[t]{5}{*}{$\mathbf{r}$} & 50 & .2399 & .1688 & * & * \\
\hline & 100 & .1079 & .0634 & .1014 & .0671 \\
\hline & 150 & .0716 & .0453 & .0665 & .0444 \\
\hline & 300 & .0325 & .0233 & .0332 & .0219 \\
\hline & 500 & .0202 & .0138 & .0200 & .0134 \\
\hline
\end{tabular}


Tab1e 6 (continued)

P

36

72

m

m

RMS $_{i}($ diag ) N

9

6

9

6

\begin{tabular}{|c|c|c|c|c|c|}
\hline \multirow[t]{5}{*}{$\underline{\mathbf{s}}$} & 50 & .2425 & .1840 & * & * \\
\hline & 100 & .0719 & .0089 & .0291 & .0158 \\
\hline & 150 & .0253 & .0063 & .0039 & .0000 \\
\hline & 300 & .0000 & .0000 & .0000 & .0000 \\
\hline & 500 & .0000 & .0000 & .0000 & .0000 \\
\hline \multirow[t]{5}{*}{ k } & 50 & .2812 & .2274 & * & * \\
\hline & 100 & .0826 & .0109 & .0332 & .0191 \\
\hline & 150 & .0289 & .0077 & .0045 & .0000 \\
\hline & 300 & .0000 & .0000 & .0000 & .0000 \\
\hline & 500 & .0000 & .0000 & .0000 & .0000 \\
\hline
\end{tabular}


Table 7

Ayerage_RMSc( diag) +_RMS

Eafferns_yitb_+40_Loadings

$\mathrm{p}$

36

72

D

$\operatorname{RMS}_{i}(\mathrm{diag}) \mathrm{N}$

9

6

9

6

\begin{tabular}{|c|c|c|c|c|c|}
\hline \multirow[t]{5}{*}{$\underline{c}$} & 50 & .8818 & .7473 & * & * \\
\hline & 100 & .6525 & .3988 & .7455 & .1711 \\
\hline & 150 & .5364 & .3193 & .4778 & .1254 \\
\hline & 300 & .2969 & .0866 & .1046 & .0655 \\
\hline & 500 & .0967 & .0422 & .0637 & .0399 \\
\hline \multirow[t]{5}{*}{$\mathbf{r}$} & 50 & .8523 & .7475 & * & $\star$ \\
\hline & 100 & .6667 & .3904 & .7274 & .1948 \\
\hline & 150 & .5379 & .3331 & .4889 & .1430 \\
\hline & 300 & .2987 & .0995 & .1154 & .0756 \\
\hline & 500 & .1044 & .0498 & .0703 & .0467 \\
\hline
\end{tabular}


Table 7 (continued)

RMS $_{i(\text { diag) }}$

9

6

9

6

\begin{tabular}{|c|c|c|c|c|c|}
\hline \multirow[t]{5}{*}{ 오 } & 50 & .9057 & .7901 & * & $\star$ \\
\hline & 100 & .6969 & .4261 & .7776 & .1154 \\
\hline & 150 & .5369 & .3230 & .4645 & .0561 \\
\hline & 300 & .2791 & .0309 & .0044 & .0119 \\
\hline & 500 & .0379 & .0000 & .0000 & .0000 \\
\hline \multirow[t]{5}{*}{$\mathbf{k}$} & 50 & .9564 & .8685 & * & * \\
\hline & 100 & .7515 & .4828 & .8134 & .1386 \\
\hline & 150 & .5707 & .3675 & .4815 & .0668 \\
\hline & 300 & .2954 & .0368 & .0049 & .0145 \\
\hline & 500 & .0429 & .0000 & .0000 & .0000 \\
\hline
\end{tabular}


Table 8

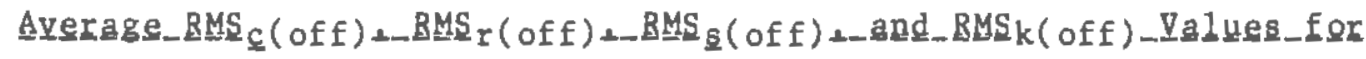

Patterns_xith_80_Loadings

RMS $_{i}$ ( off) N

9

6

9

6

\begin{tabular}{|c|c|c|c|c|c|}
\hline \multirow[t]{5}{*}{ c } & 50 & .0722 & .0856 & * & * \\
\hline & 100 & .0472 & .0495 & .0485 & .0478 \\
\hline & 150 & .0426 & .0359 & .0364 & .0403 \\
\hline & 300 & .0267 & .0294 & .0270 & .0269 \\
\hline & 500 & .0228 & .0220 & .0223 & .0237 \\
\hline \multirow[t]{5}{*}{$\mathbf{r}$} & 50 & .1399 & .2100 & * & * \\
\hline & 100 & .1307 & .2029 & .1311 & .2019 \\
\hline & 150 & .1301 & .2011 & .1283 & .2021 \\
\hline & 300 & .1271 & .2012 & .1270 & .2005 \\
\hline & 500 & .1266 & .2006 & .1263 & .2005 \\
\hline
\end{tabular}


Table 8 (continued)

36

72

田

m

RMS $_{i}$ ( off) N

9

6

9

6

\begin{tabular}{|c|c|c|c|c|c|}
\hline \multirow[t]{5}{*}{$\underline{\mathbf{B}}$} & 50 & .0262 & .0318 & * & * \\
\hline & 100 & .0000 & .0000 & .0000 & .0000 \\
\hline & 150 & .0000 & .0000 & .0000 & .0000 \\
\hline & 300 & .0000 & .0000 & .0000 & .0000 \\
\hline & 500 & .0000 & .0000 & .0000 & .0000 \\
\hline \multirow[t]{5}{*}{$\mathbf{k}$} & 50 & .0125 & .0000 & * & * \\
\hline & 100 & .0000 & .0000 & .0000 & .0000 \\
\hline & 150 & .0000 & .0000 & .0000 & .0000 \\
\hline & 300 & .0000 & .0000 & .0000 & .0000 \\
\hline & 500 & .0000 & .0000 & .0000 & .0000 \\
\hline
\end{tabular}


Table 9

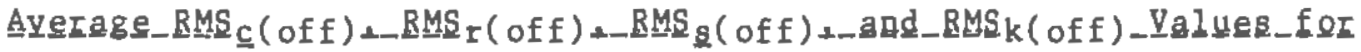

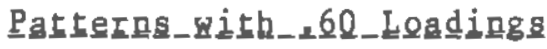

P

36

72

II

II

$\operatorname{RMS}_{i}($ off $) \quad N$

9

6

9

6

\begin{tabular}{|c|c|c|c|c|c|}
\hline \multirow[t]{5}{*}{$\underline{c}$} & 50 & .1036 & .0941 & * & * \\
\hline & 100 & .0577 & .0465 & .0559 & .0496 \\
\hline & 150 & .0448 & .0357 & .0378 & .0403 \\
\hline & 300 & .0295 & .0292 & .0286 & .0296 \\
\hline & 500 & .0201 & .0247 & .0232 & .0219 \\
\hline \multirow[t]{5}{*}{$\mathbf{I}$} & 50 & .1453 & .1959 & * & $\star$ \\
\hline & 100 & .1277 & .1942 & .1273 & .1945 \\
\hline & 150 & .1256 & .1951 & .1235 & .1959 \\
\hline & 300 & .1249 & .1979 & .1245 & .1979 \\
\hline & 500 & .1244 & .1993 & .1249 & .1989 \\
\hline
\end{tabular}


Table 9 (continued)

p

36

72

m

Ш

RMS $i$ ( off) N

9

6

9

6

\begin{tabular}{|c|c|c|c|c|c|}
\hline \multirow[t]{5}{*}{$\underline{\mathbf{s}}$} & 50 & .1040 & .0880 & * & * \\
\hline & 100 & .0489 & .0079 & .0167 & .0119 \\
\hline & 150 & .0179 & .0056 & .0028 & .0000 \\
\hline & 300 & .0000 & .0000 & .0000 & .0000 \\
\hline & 500 & .0000 & .0000 & .0000 & .0000 \\
\hline \multirow[t]{5}{*}{$k$} & 50 & .0546 & .0261 & * & * \\
\hline & 100 & .0264 & .0000 & .0000 & .0000 \\
\hline & 150 & .0091 & .0000 & .0000 & .0000 \\
\hline & 300 & .0000 & .0000 & .0000 & .0000 \\
\hline & 500 & .0000 & .0000 & .0000 & .0000 \\
\hline
\end{tabular}


Table 10

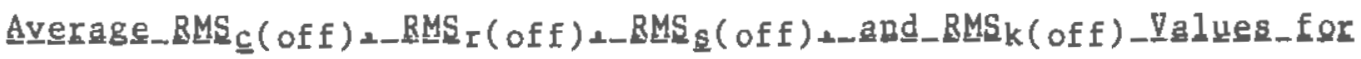

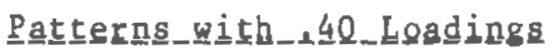

36

72

I.

m

RMS $_{i}$ (off) N

9

6

9

6

\begin{tabular}{|c|c|c|c|c|c|}
\hline \multirow[t]{5}{*}{$\subseteq$} & 50 & .2333 & .2621 & $\star$ & * \\
\hline & 100 & .2008 & .1575 & .2097 & .0618 \\
\hline & 150 & .1704 & .1448 & .1446 & .0514 \\
\hline & 300 & .1095 & .0403 & .0339 & .0272 \\
\hline & 500 & .0433 & .0264 & .0236 & .0196 \\
\hline \multirow[t]{5}{*}{$I$} & 50 & .2364 & .2796 & * & * \\
\hline & 100 & .2166 & .2146 & .2218 & .1754 \\
\hline & 150 & .1969 & .2258 & .1779 & .1799 \\
\hline & 300 & .1578 & .1865 & .1163 & .1872 \\
\hline & 500 & .1223 & .1926 & .1190 & .1918 \\
\hline
\end{tabular}


Table 10 (continued)

$$
\mathrm{P}
$$

36

72

II

II

RMS $_{i}$ (off) N

9

6

9

6

\begin{tabular}{|c|c|c|c|c|c|}
\hline \multirow[t]{5}{*}{$\underline{\mathbf{g}}$} & 50 & .2031 & .2261 & * & * \\
\hline & 100 & .1828 & .1535 & .1968 & .0474 \\
\hline & 150 & .1608 & .1256 & .1399 & .0214 \\
\hline & 300 & .1025 & .0112 & .0000 & .0000 \\
\hline & 500 & .0182 & .0000 & .0000 & .0000 \\
\hline \multirow[t]{5}{*}{$k$} & 50 & .1495 & .1357 & * & * \\
\hline & 100 & .1315 & .0807 & .1661 & .0009 \\
\hline & 150 & .1205 & .0806 & .1134 & .0006 \\
\hline & 300 & .0809 & .0000 & .0000 & .0000 \\
\hline & 500 & .0115 & .0000 & .0000 & .0000 \\
\hline
\end{tabular}


values. This relationship is referred to as the simple model. For each index, separate analyses were performed for $R M S_{i}\left(d_{i a g}\right)$ and $R M S_{i}(o f f) \cdot$ Although the focus of this study related to the effect of $N, p$, $m$, and $a_{i j}$ on index performance, additional models were also examined. These models included several transformations of the original independent variables. For example, $\mathrm{N}^{-1 / 2}$, a transformation suggested by the standard error of a correlation coefficient, and $\mathrm{p} / \mathrm{m}$, the number of variables per component, were employed. Regression solutions were not significantly improved when these transformations were included. For this reason and for the sake of simplicity of interpretation, results are provided only for the simple model.

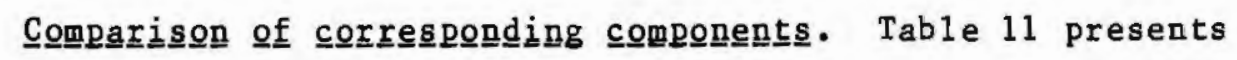
regression statistics resulting from application of the simple model to prediction of RMS $_{\underline{c}}$ (diag), $\operatorname{RMS}_{\mathbf{r}}\left(\mathrm{diag}_{\mathrm{d}}\right), \mathrm{RMS}_{\underline{\mathbf{s}}}(\mathrm{diag})$, and $\mathrm{RMS}_{\mathbf{k}}\left(\mathrm{diag}_{\mathrm{g}}\right)$. In all cases a multiple $R$ of $>.70$ was obtained. The performance of each index was influenced by both $a_{i j}$ and $N$. Lower RMS $i(d i a g)$ values (index values close to the expected value of 1.00 ) were associated with higher values of $a_{i j}$ and increased $N$. For each index, $a_{i j}$ surfaced as the more important variable as evidenced by its larger standarized regression coefficient. The regression coefficients associated with both $p$ and $m$ were not significant.

The relationship of $a_{i j}$ and $N$ on matching performance may be observed in Tables 5 through 7. For all statistics, RMS $i(d i a g)$ values were $<.10$ for $N>100$ at $a_{i j}=.60$ and $a_{i j}=.80$. RMS $i(d i a g)$ values in this range reflect index values $>.90$. At $a_{i j}=.40$, the influence of $N$ on RMS $_{i}$ (diag) values was more obvious than at higher $a_{i j}$. Larger sample 
Table 11

Multiple_Begregeion_Begults_from_Prediction_of_BMS i(diag)_Vsing the_Simple_Model

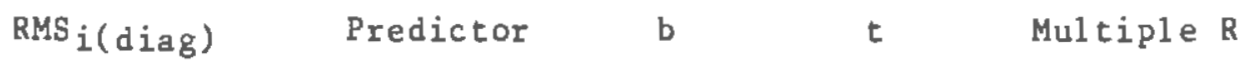

\begin{tabular}{|c|c|c|c|c|}
\hline \multirow[t]{4}{*}{$\underline{\mathrm{c}}$} & $a_{i j}$ & -.591 & $-6.29 * \star \star$ & .75 \\
\hline & N & -.394 & $-4.15 * * \star$ & \\
\hline & $\mathrm{P}$ & -.120 & -1.26 & \\
\hline & m & .188 & 1.99 & \\
\hline \multirow[t]{4}{*}{$\mathbf{r}$} & $a_{i j}$ & -.605 & $-6.59 * * *$ & .77 \\
\hline & N & -.401 & $-4 \cdot 33 * * *$ & \\
\hline & $P$ & -.118 & -1.28 & \\
\hline & $\mathbf{m}$ & .183 & 1.99 & \\
\hline \multirow[t]{4}{*}{ 오 } & $a_{i j}$ & -.533 & $-5.28 \star \star \star$ & .71 \\
\hline & $\mathbf{N}$ & -.386 & $-3.79 * \star \star$ & \\
\hline & P & -.152 & -1.49 & \\
\hline & m & .171 & 1.69 & \\
\hline \multirow[t]{4}{*}{ k } & $a_{i j}$ & -.536 & $-5 \cdot 35 * * *$ & .71 \\
\hline & $N$ & -.393 & $-3.89 \star \star \star$ & \\
\hline & p & -.160 & -1.58 & \\
\hline & $\mathbf{m}$ & .159 & 1.58 & \\
\hline
\end{tabular}


sizes were required for RMS $_{i}$ (diag) values to approach 0.0 .

Comparison of nonn=corresponding components. The regression statistics obtained following application of the simple model separately

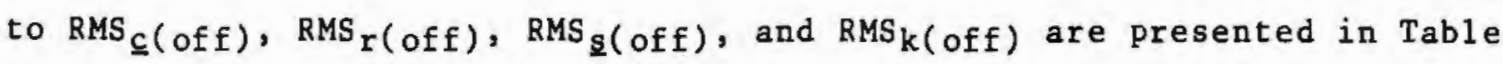
12. For all cases, the $f$ it of the model was reasonably good as indicated by multiple Rs of $>.70$. Variables influencing RMS (off) were not consistent across indices.

Both increased $a_{i j}$ and $N$ improved $R^{M} S_{\mathcal{C}}$ (off) performance. The standardized regression weights reveal that $\mathrm{N}$ surfaced as the primary influence. While the same variables, in addition to $p$, influenced RMS $_{\underline{S}}$ (off) performance, $a_{i j}$ asserted the major influence. Higher values of $a_{i j}$ were associated with lower values of RMS g $_{\text {g }} f$ ). For both RMS $_{r}($ off $)$ and $\operatorname{RMS}_{k}($ off $), a_{i j}, N$, and $m$ affected the quality of matching performance. The major influence on $R M S_{I}$ (off) was m. RMS $($ off) values decreased with an increase in the number of components. RMS $_{k}($ off $)$ performance was influenced most by $a_{i j} \cdot R S_{k}($ off $)$ approached the expected value $(0.0)$ at larger levels of $a_{i j}$. In addition, $\operatorname{RMS}_{k}$ (off) values decreased with decreased m.

Tables 8 through 10 provide further evidence of the relationships between the variables manipulated and the quality of non-corresponding component matching performance. Al1 RMS $\mathrm{C}_{\mathfrak{\subseteq}}($ off $), \mathrm{RMS}_{\underline{\mathbf{s}}}($ off $)$, and $\mathrm{RMS}_{\mathrm{k}}$ (off) values were $\left\langle .10\right.$ at $N>100$ for $a_{i j}=.60$ and $a_{i j}=.80$. RMS $i$ (off) values within this range reflect index values $<.10$. At $a_{i j}=.40$, the influence of $N$ on matching performance was more obvious than at higher saturation levels. Greater values of $\mathrm{N}$ were required to yield RMS $\mathrm{i}$ (off) values which approached 0.0 . Under no conditions were RMS $r$ (off) values 
Table 12

Mulfiple_Regression_Resulth_from___rediction_of_BMS $i$ (off)_lsing the. Simple_Model

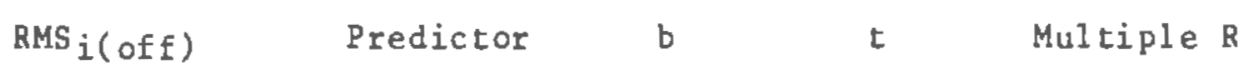

\begin{tabular}{|c|c|c|c|c|}
\hline \multirow[t]{4}{*}{ c } & $a_{i j}$ & -.486 & $-5.21 * * *$ & \multirow[t]{4}{*}{.76} \\
\hline & $\mathbf{N}$ & -.514 & $-5 \cdot 46 * \star \star *$ & \\
\hline & $\mathrm{P}$ & -.186 & -1.98 & \\
\hline & m & .124 & 1.33 & \\
\hline \multirow[t]{4}{*}{$\mathbf{r}$} & $a_{i j}$ & -.236 & $-2.85 * * \star$ & \multirow[t]{4}{*}{.81} \\
\hline & N & -.240 & $-2.87 * * \star *$ & \\
\hline & $P$ & -.121 & -1.44 & \\
\hline & m & -.726 & 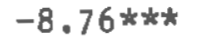 & \\
\hline \multirow[t]{4}{*}{$\mathbf{g}$} & $a_{i j}$ & -.549 & $-5.85 * * *$ & \multirow[t]{4}{*}{.75} \\
\hline & N & -.431 & $-4.55 * * \star$ & \\
\hline & $P$ & -.197 & $-2.08 \star$ & \\
\hline & m & .143 & 1.53 & \\
\hline \multirow[t]{4}{*}{$\mathbf{k}$} & $a_{i j}$ & -.531 & $-5.26 * \star \star *$ & \multirow[t]{4}{*}{.71} \\
\hline & $\mathrm{N}$ & -.356 & $-3.49 * * \star$ & \\
\hline & $\mathrm{P}$ & -.161 & -1.59 & \\
\hline & m & .226 & $2.24 *$ & \\
\hline
\end{tabular}

$\star P<.05$

$* * * \mathrm{P}<.001$ 
below .10 . At $a_{i j}=.60$ and $a_{i j}=.80$ relatively constant RMS (off) values were associated with each level of m employed. At $a_{i j}=4.0$ consistent relationships between $\mathrm{RMS}_{\mathrm{r}}(\mathrm{off})$ and $\mathrm{N}, \mathrm{m}$, and $\mathrm{p}$ are difficult to discern. It does appear, however, that for equal m and $N R^{2} S_{\text {(of }}$ ) values associated with $\mathrm{p}=72$ were lower than values associated with $\mathrm{p}=$ 36.

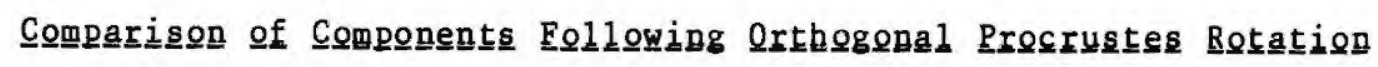

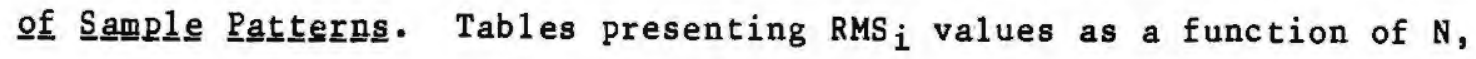
$p$, and $m$ at each level of $a_{i j}$, obtained following Procrustes rotation, are displayed in Appendix A. These results did not differ a great deal from results following varimax rotation. This is not surprising since population matrices employed in this design were orthogonally constructed. Comparison at the $a_{i j}=.80$ and the $a_{i j}=.601$ evels yielded $\mathrm{RMS}_{i}$ values which were nearly identical to values presented in previous sections. At $a_{i j}=.40$, Procrustes rotation did improve comparison between population and sample patterns with 1 ow $\mathrm{p} / \mathrm{m}$ ratios and when $N \leq 300$. Improvement over varimax results was generally greater for comparison of non-corresponding components.

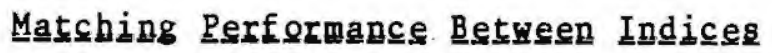

\section{Comparison of corresponding components. Figure 1 displays the} relationship of $\mathrm{N}$ to $\mathrm{RMS}_{\mathrm{i}}$ (diag) collapsed across levels of $\mathrm{p}, \mathrm{m}$, and $a_{i j}$. It is evident from this plot that, at equivalent levels of $\mathrm{N}$, all indices yielded similar deviations from the expected value (1.00). Also evident is the relationship between $\mathrm{RMS}_{\mathrm{i}}(\mathrm{diag})$ and $\mathrm{N}$ discussed 


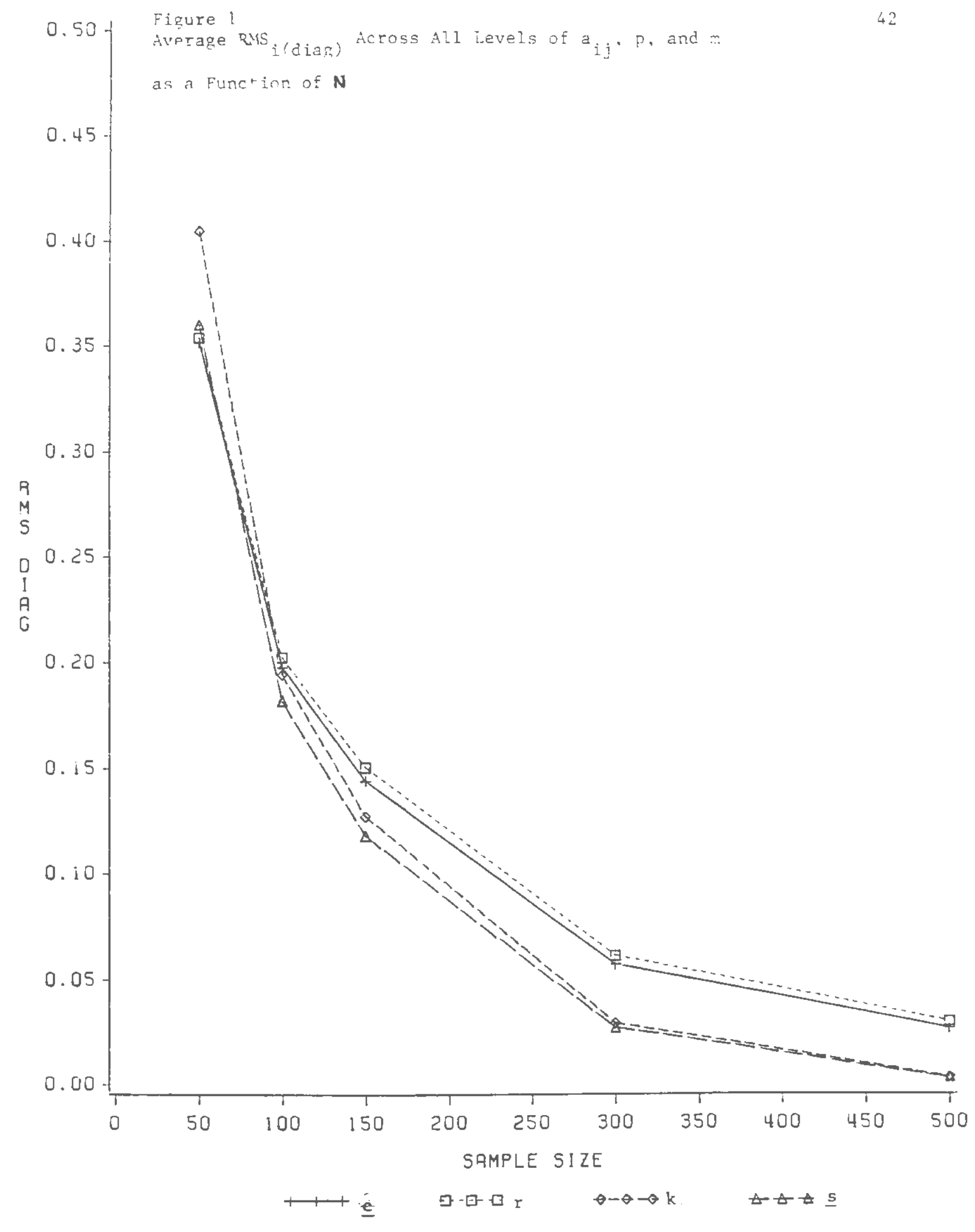


previously. The ability of indices to yield deviations close to the expected value increased with sample size. Examination of RMSi(diag) values in Tables 5 to 7 also indicate that the variability in RMS (diag) values across indices decreased with increased N. No index

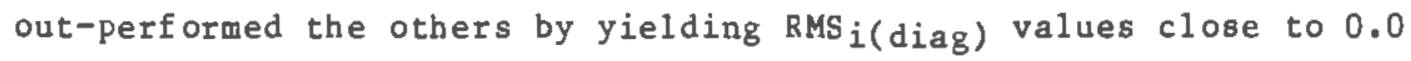
across all levels of $\mathrm{N}$. The homogeneity of $\mathrm{RMS}_{\mathrm{i}}$ (diag) values is further observed in Table 13. In this table, the intercorrelations of

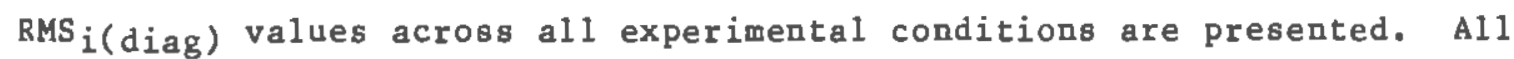
correlation coefficients exceed .99.

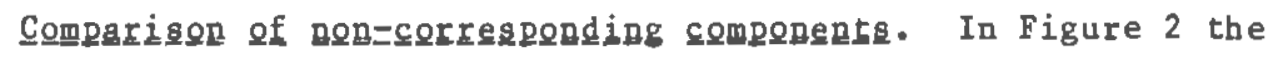
relationship of RMS $_{i}$ (off) to $N$ collapsed across levels of $p$, w and $a_{i j}$ is presented. This plot reveals greater variability in matching performance than occurred when correaponding components were matched. Relative to other indices, RMS $r($ off) values were high. RMS (off) values associated with $q$ and $k$ resulted in the smaller deviations between expected and observed index values. RMS $_{c}($ of $f$ ) values were closer to those of RMS g $_{\text {(off) }}$ and RMS $_{\mathrm{k}}$ (off) than to RMS $\mathrm{f}$ (off). The intercorrelations between RMS $i$ (off) values is presented in Table 14. The lack of similarity between RMS $_{r}($ off $)$ and the other RMS $($ off) valuea is evident in this table.

For $s, k$, and $c, R_{i}$ (of $f$ ) values approached 0.0 with increasing

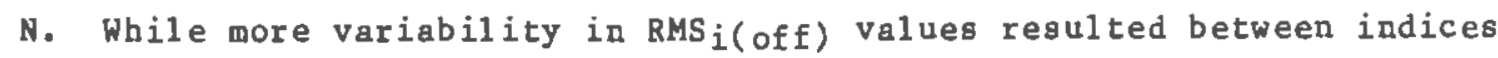

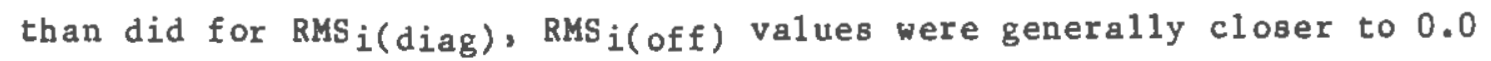
at each leve1 of $\mathrm{N}$.

RMS $_{i}$ (diag) and RMS $($ off) values plotted in Figures 1 and 2 are collapsed for ease of interpretation. Index values associated with 
Tab1e 13

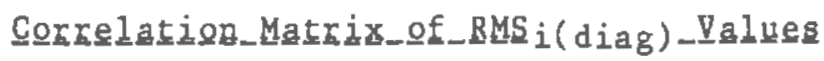

$$
\text { RMS }_{\underline{c}(\mathrm{diag})} \quad \mathrm{RMS}_{\mathbf{r}(\mathrm{diag})} \mathrm{RMS}_{\mathrm{Q}}(\mathrm{diag}) \quad \mathrm{RMS}_{\mathrm{k}}(\mathrm{diag})
$$

RMS $_{\underline{\underline{c}}}$ (diag) 1.0000

RMS $_{\mathbf{r}}$ (diag) $\quad .9994 \quad 1.0000$

$\begin{array}{llll}\text { RMS }_{\mathrm{S}} \text { (diag) } & .9945 & .9927 & 1.0000\end{array}$

$\begin{array}{lllll}\text { RMS }_{\mathrm{k}}(\mathrm{diag}) & .9929 & .9918 & .9994 & 1.0000\end{array}$ 


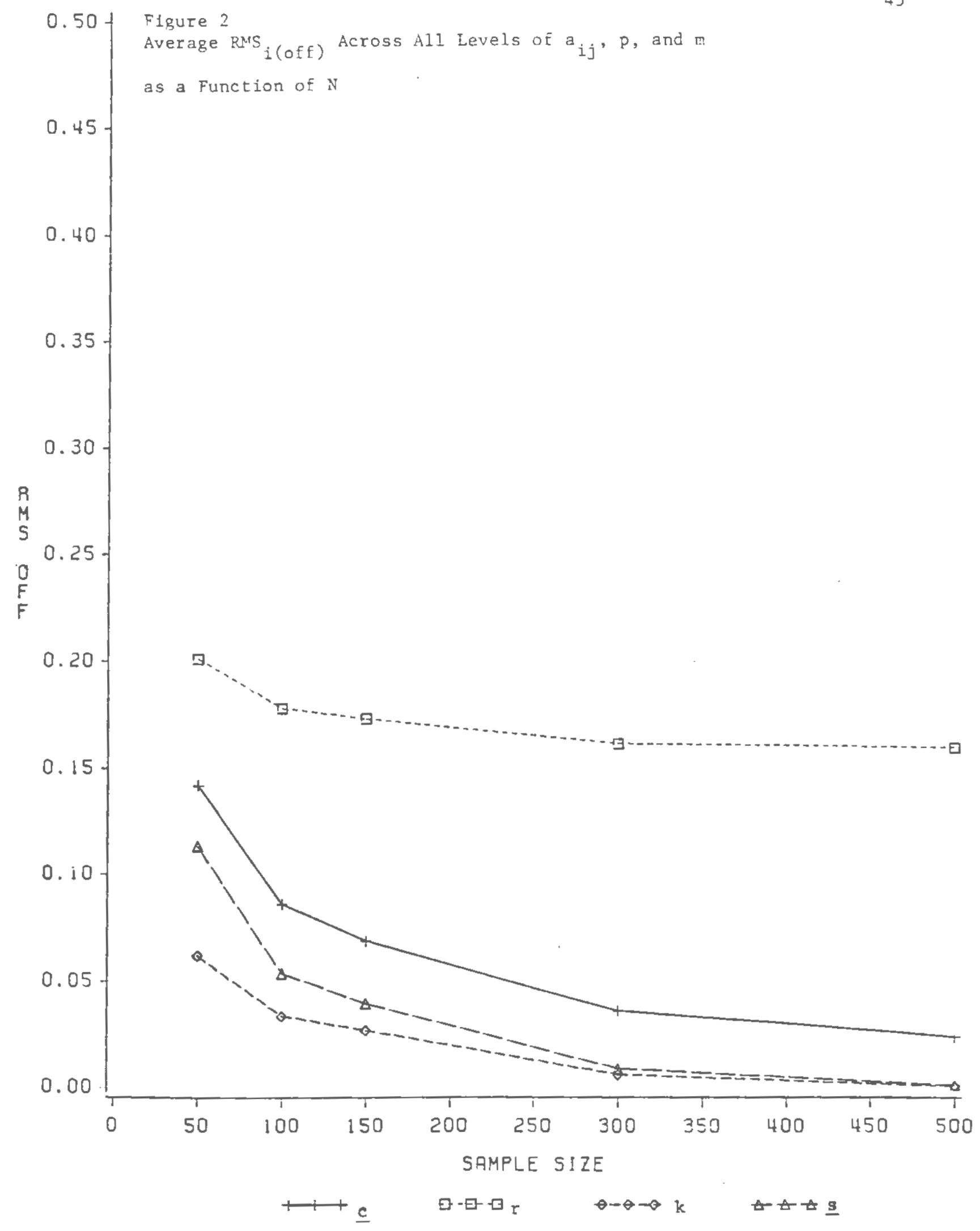


Table 14

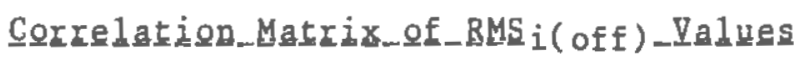

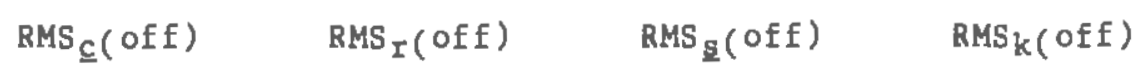

$\operatorname{RMS}_{\subseteq}(\mathrm{Off}) \quad 1.0000$

RMS $_{I}$ (off $) \quad .5355 \quad 1.0000$

$\begin{array}{llll}\mathrm{RMS}_{\mathrm{g}} \text { (off) } & .9823 & .5015 & 1.0000\end{array}$

$\begin{array}{lllll}\text { RMS }_{k}(\text { off }) & .9572 & .4667 & .9735 & 1.0000\end{array}$


resulting RMS values at each level of $N(e . g \cdot k=.60$ would be associated with RMS $_{\mathrm{k}}(\mathrm{diag})=.40$ at $\mathrm{N}=50$ in Figure 1 and $\mathrm{k}=.06$ would be associated with $\mathrm{RMS}_{\mathrm{k}}$ (off) $=.06$ at $N=50$ in Figure 2 ) should not be interpreted as the index value which results when components are matched at that level of $N$. That is, the values plotted in these figures are not benchmarks. One can not say that $k=.60$ is the index value expected when comparing components obtained from solutions generated with an $N$ of 50 . Tables 5 to 10 and the within index results discussed above indicated that for each index, variability in RMS values exists at each level of $N$. This variability resulted from the influence of the variables manipulated (primarily $a_{i j}$ ). 


\section{Discussion}

The purpose of this investigation was to assess performance of several component matching indices, $c, r, s$, and $k$, under a variety of experimental conditions. Index performance both within indices and between indices was assessed. With the exception of $r$, little difference in matching performance was observed. For all practical purposes, comparison performance for $c, s$, and $k$ was indistinguishable when both corresponding components and non-corresponding components were compared. Performance of $r$, relative to the other indices, was particularly poor when non-corresponding components were compared.

No index was free of the influence of the variables manipulated. When components expected to match (corresponding components) were compared, $N$ and $a_{i j}$ influenced matching performance. An increase in the magnitude of each of these factors resulted in more accurate performance for each index. The effect of the variables manipulated on comparison of non-corresponding components was not as consistent. In addition to $N$ and $a_{i j}$, m influenced the performance of $r$ and $k$, while $p$ influenced $s$ performance. A direct implication of the influence of $p$ and $m$ is the level of $\mathrm{p} / \mathrm{m}$, the ratio of salient variables per component. For $\mathrm{g}$ and $\mathrm{k}$ theae results indicate that when better defined non-corresponding components (high $\mathrm{p} / \mathrm{m}$ ratio) were matched, lower index values resulted. 
The opposite was true for $r$. Here, comparison of more poorly defined components yielded lower index values. Given the non-additive properties of $r$, less accurate results were not unexpected under high p/m conditions since, by definition, a greater number of extreme (salient) values were present. The greater the number of salient values present, the more likely the mean value of the component, and therefore deviations from the mean, will not be accurately represented.

Relative to the conditions appropriate for the performance of PCA (i. e. the presence of well defined components in terms of component saturation or $\mathbf{N} \geq 300$ under less well defined conditions (Guadagnoli \& Velicer, 1986)) $\subseteq, \underline{s}$ and $\mathbf{k}$ provided average index values greater than .90 when corresponding components were compared and less than .10 when non-corresponding components were compared. Decisions made relative to the similarity of components based on any index would, therefore, be similar. This result reinforces the idea of identifiability relative to component solutions. Poorly defined components $(p / m \leq 4,1$ ow component saturation) generated under low sample size conditions (N< 300$)$ do not yield components which match their underlying population structure. This conclusion will be drawn whatever the matching index employed to assess similarity.

While decisions made relative to $\underline{c}, \underline{s}$ and $k$ would be consistent, the actual index values obtained did vary. If forced to choose one index over all others, one might assess index performance relative to perfect matching performance. That is, one could determine the frequency of average index values of 1.00 when corresponding components were compared and 0.00 for comparison of non-corresponding components. 
Employing this criterion, $\underline{s}$ and $k$ performance was superior to $\underline{c}$ performance. Under either comparison situation, $\subseteq$ never attained perfect performance. Both $s$ and $k$ provided average values of 1.00 when corresponding components were matched in $52 \%$ of the conditions examined. This percentage was even higher when non-corresponding components were matched. The statistic provided perfect performance for $56 \%$ of the conditions examined, while $\mathrm{k}$ met this criterion $69 \%$ of the time. These results support Cattell's (1984) and Baker's (1973) contention that $\mathbf{s}$ is a more reliable index than $c$. Evaluation of the configuration of hyperplane and non-hyperplane variables as assessed by $\underline{s}$ and $k$ rather than the invariance of component loadings accounts for the differences observed in perfect performance between these statistics and $\underline{c}$. Relative to the population patterns employed in this design, the computational simplicity associated with $k$ as a result of ignoring the sign of salient variables did not sacrifice matching accuracy.

In addition to the major finding of this study, several other points emerged. A criticism of $\subseteq$ has been the expected occurrence of high values when components containing variables of the same sign and a high proportion of salient component loadings, without respect to the pattern of loadings, are compared (Pinneau \& Newhouse, 1964). This suggests that comparison of non-corresponding components should result in large rather than small $\subseteq$ values. Within the context of the present study, this did not occur. Under no condition examined did comparison of non-corresponding components result in average $c$ values which exceeded .30 . The generation of high $s$ values under these conditions is, therefore, not an inherent characteristic of this index. 
The need for significance tables to interpret similarity statistics does not appear to be required. Under conditions of the present study, the performance of $s, k$ and $\subseteq$, support Walkey and McCormick's (1985) notion that "...the concept of factor replication [can be] considered in the same way as reliability, that is, with the aim being to achieve an index approaching unity rather than differing from zero." (p. 65). Al1 indices yielded high ( $\geq .90)$ values under conditions known to match and low values $(\leq .10)$ when components were known to differ (when conditions were appropriate for performance of PCA). While observed values were close to expected values under the rather ideal conditions examined here, this may not be the case when data more reflective of applied conditions are employed.

These results basically confirm the few empirical studies in the literature. Derogatis et al. (1972) and Reynolds and Harding (1983) concluded that major differences did not occur in the performance of $\underline{c}$ and $s$ and that conclusions based on either statistic would not vary. Here, little difference in index performance was reported. Conditions assessed in the present study were more extensive, however, and comparison of both corresponding and non-corresponding performance was assessed. It is suspected that Reynolds and Harding (1983) would have observed the poor performance of $r$ had they examined comparison of non-corresponding components.

Conclusions reported here would be consistent when Factor Analysis methods other component analysis are employed. Results obtained are not method specific. The problem under consideration was comparison of a sample p x m matrix to its population solution. The ability of the 
index to indicate congruence or non-congruence will not depend on the content (factor loadings vs component loadings) of the $\mathrm{p} x \mathrm{~m}$ matrices. Conclusions may differ, however, under conditions representing more complex population patterns. The inclusion of unique and complex items, in addition to varied saturation, within the population pattern may affect the accuracy of index performance. These conditions would be expected to perturb the specific values of component loadings (more than the conditions employed in this design) and should, therefore, negatively affect the accuracy of $c$. Employing these conditions in future designs will determine whether the value of sample component loadings change to such a degree as to decrease the accuracy of $\underline{s}$ and k. A related issue is the choice of hyperplane bound when $\underline{s}$ or $k$ are calculated. In this study .30 was employed. As the hyperplane bound approaches the level of salient loadings in the population, one would expect the performance of $s$ and $k$ to breakdown under certain conditions. Index performance will be accurate only when the value of sample component loadings do not vary from population loadings. Under conditions when this is not likely to occur $(\mathrm{N}<300,1$ ow $\mathrm{p} / \mathrm{m}$ ) errors in deciding salience and non-salience will result and therefore the performance of $\underline{s}$ and $k$ should be negatively influenced.

To summarize, the matching performance of $s, s$, and $k$ when comparing corresponding and non-corresponding population components to sample components was essentially indistinguishable. Index performance was primarily influenced by $a_{i j}$ and $N$. No index produced accurate values under all experimental conditions. Under conditions appropriate for PCA (Guadagnoli \& Velicer, 1986), however, each index yielded 
similar results. Average index values were $\geq .90$ when corresponding components were compared and $\leq .10$ for comparison of non-corresponding components. Both $g$ and $k$ produced perfect results in greater than $50 \%$ of the conditions examined. Perfect performance was never attained for c. The use of I as a viable matching index was not supported due to its poor matching performance relative to non-corresponding components. 
Footnote

1prior to the formalization of this design five samples were generated for several conditions and a general comparison statistic, $g$ (Guadagnoli \& Velicer, 1986), was calculated as an indicator of similarity between the population pattern and each sample pattern. The standard error of the mean derived from the five comparison statistics generated for each cell was smal1. Further, for the case in which $\mathrm{p}=$ 36, $a_{i j}=.40, m=6$ and $N=150$, five, ten and fifteen sample correlation matrices were generated and resulting mean gs and standard errors compared. Means and standard errors differed only in the fifth decimal place. These results suggest that five samples per cell are adequate to produce comparison statistics which are stable. 
References

Ahmavara, Y. (1954). Transformation analysis of factorial data. Annales Academiae Scientiarum Fenniçal, Series B, (Helsinki), 8q, 54-59. Andresen, B., Stemmler, G., Thom, E., \& Irrganz, E. (1984).

Metbodological conditions of congruent factors: A comparison of EEG frequency structure between bemispheres. Multiyariate

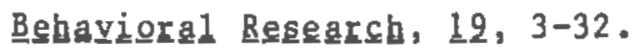

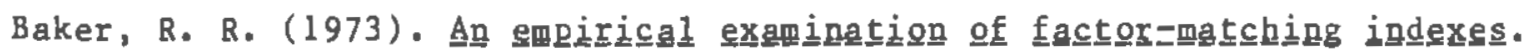
(Psychological Documents No. 465). Washington, DC: American Psychological Association. Baltes, P. B., Eyferth, K., \& Schaie, R. W. (1969). Intra - and intercultural factor structures of social desirability ratings by American and German college students. Multiyariate Bebayioral Resesearch , 4, 67-78. Burt, C. L. (1948). The factorial study of tempermental traits. British

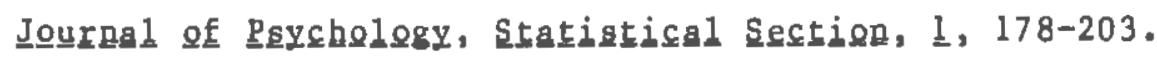
Cattel1, R. B. (1949). A note on factor invariance and the identification of factors. British Jourpal of Pgychology, 2, 134-138. Cattell, R. B. (1978). The scientific use of factor anglygis in bęhayiorgl and lif́ sciencess. New York: Plenum Press. Cattel1, R. B. (1984). The voyage of a laboratory, 1928 - 1984. Multiyariate Behayioral Besearch, 19, 121-174. Cattel1, R. B., \& Baggaley, A. R. (1960). The oalient variable similarity index for factor matching. Britigh Journal of Statistical

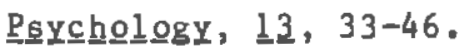


Cattell, R. B., Balcar, K. R., Horn, J. L., \& Nesselroade, J. R. (1969)

Factor matching procedures: An improvement of the $\mathrm{s}$ index; with tables. Educational and Psychological Measurement, 29, 781-792.

Cliff. N. (1966). Orthogonal rotation to congruence. Bsychometrika, 31 , 33-42.

Cohen, J. (1960). A coefficient of agreement for nominal scales. Educatiㅡㅁㅁaㄱ and Psycybologiçal Measurement, 20, 37-46.

Cohen, J. (1969). Ic: A profile similarity coefficient invariant over variable reflection. Psychological Bulletin, ZL, 281-284.

Cureton, E. E., \& D'Agostino, R. B. (1983). Factor analysis: An applied apProach. Hillsdale, NJ: Lawrence Erlbaum.

Derogatis, L. R., Serio, J. C., \& Cleary, P. A. (1972). An empirical comparison of three indices of factorial similarity. Peycbological Repotsa, 30, $791-804$.

Fleiss, J. L. (1981). Statistical metbode for rates and proportions.

(2nd ed.). New York: John Wiley and Sons.

Glass, G., \& Taylor, P. A. (1966). Factor analytic methodology. Reyien of Educational Research. $36,566-587$.

Gorsuch, R. L. (1983). Factor anglygia (2nd Ed.) Hillsdale, NJ : Lawrence Erlbaum.

Guadagnoli, E. \& Velicer. W. F. (1986). Tbe relationship of sample size to the stability of sample component patterns: A simulation study. Manuscript Gubritted for publication.

Horn, J. L., Mc Ardle, J. J., Mason, R. (1983). When is invariance not invariant: A practical scientist's look at the ethereal concept of factor invariance. The Southern Pgycbologist, $1,179-188$. 
Hotelling, H. (1933). Analysis of a complex of statistical variables into principal components. Jourrnal of Educational Psychology, 244, 417-441, 498-520.

Jackson, D. N. \& Chan, D. W. (1980). Maximum - likelihood estimation in common factor analysis: A cautionary note. Psychological Bulletin, 88, $502-508$.

Joreskog, R. G. (1969). A general approach to confirmatory maximum likelihood factor analysis. Psychometrika, 34, 183-202. Kaiser, H. F. (1958). The varimax criterion for analytic rotation in factor analysis. Psychometrikkㅡ, 23, 187-200.

Kaiser, H. F., Hunka, S., \& Bianchini, J. C. (1971). Relating factors between studies based upon different individua1s. Mulfivariates Behagyiora1 Besearch, $6,409-422$.

Korth, B., \& Tucker, L. R. (1975). The distribution of chance congruence coefficients from simulated data. Psychometrika, 4l, 361-372.

Landis, J. R., \& Koch, G. G. (1977). The measurement of observer agreement for categorical data. Biometrics, 33, 159-174. Meredith, W. (1964). Rotation to achieve factorial invariance. Pssychometrika, 22, 187-206.

Montanelli, R. G., Jr. (1975). A computer program to generate sample correlation and covariance matrices. Educafional and Psychological

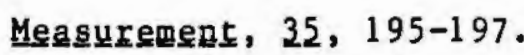

Mulaik, S. A. (1972). The foundations of factogr analysis. New York: McGraw-Bill.

Nessel roade, J. R., \& Baltes, P. B. (1970). On a dilemma of comparative factor analysis: A study of factor matching based on random data.

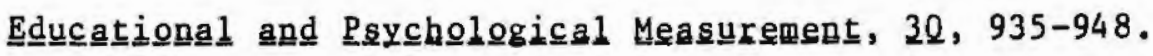


Nunnally, J. C. (1967). Psychometric theory. New York: McGraw-Hill. Nunnally, J. C. (1978). Psychometric theory (2nd Ed.). New York: McGraw-Hill.

Odel1, P. L. \& Feiveson, A. H. (1966). A numerical procedure to generate a sample covariance matrix. Journal of the American statistical Associatiog, 61, 199-203.

Pinneau, S. R., \& Newhouse, A. (1964). Measures of invariance and comparability in factor analysis for fixed variables.

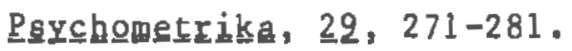

Pruzek, R. M., \& Rabinowitz, S. N. (1981). A simple method for exploratory structural analysis. American Educational Research Jouraal, 18, 173-189.

Reynolds, C. R., Harding, R. E. (1983). Outcome in two large sample studies of factorial similarity under six metbods of comparison. Educational and Esychological Measurement, 43, 723-728. Sjoberg, L., \& Holley, J. W. (1967). A measure of similarity between individuals when scoring directions are arbitrary. Multixariate Behayioral Begearch, 2, 377-384.

Steiger, J. H., \& Schonemann, P, H. (1978). A history of factor indeterminacy. In S. Shye (Ed.), Theory songtrustion and data aㅗ모곰ํㅗㄹㅗㅗ

in the behayioral sciences (PP. 136-178). San Francisco: Jossey-Bass.

ten Berge, J. M. F. (1986). Rotation to perfect congruence and the cross validation of component weights across populations. Multivariatee Behayiorgl Besearch, 21, 41-64. 
Tucker, L. R. (1951). A method for sypthesis of fac도으 analysis studies. Personnel Research Section Report No. 984. Washington, DC, Department of the Army.

Velicer, W. F. (1974). A comparison of the stability of factor analysis, principal component analysis, and rescaled image analysis.

Educcatiogal and Psychological Measurement, 34, 563-572.

Velicer. W. F. (1976). The relation between factor score estimates, image scores and principal component scores. Educational and

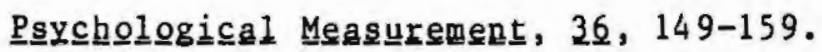

Velicer, H. F. (1977). An empirical comparison of the similarity of principal component, image, and factor patterns. Multivariate Behayioral Research, 12, 3-22.

Velicer, W. F., \& Jackson, D. N. (1985). Component analysis versus common factor analysis: Some issues in selecting an appropriate procedure. Unpublished manuscript.

Velicer, W. F., Peacock, A. C., \& Jackson, D. N. (1982). A comparison of component and factor patterns: A monte carlo approach. Multiㅡㅁaiate Behayioral Research, 1Z, 371-388.

Walkey, F. H., \& McCormick, I. A. (1985). Multiple replication of factor structure: A logical solution for a number of factors problem. Multiyariate Bebayiora1 Research, 20, 57-67. Wrigley, C. S., \& Neuhaus, J. 0. (1955). The matching of two sets of factors. Ameriçan Psycholegist, 10, 418-419. Zegers, F. E., \& ten Berge, J. M. F. (1985). A family of association coefficients for metric scales. Psychometrika, 20, 17-24. 
Zwick, W. R., \& Velicer, W. F. (1982). Factors influencing four rules for determining the number of components to retain. Multivariats Behavioral Besearch, 1Z, 253-269.

Zwick, W. R., \& Velicer, W. F. (1986). A comparison of five rules for determining the number of components in complex data sets. Bgychologisal Bulletig, 29, 432-442. 
Appendix A 
Table $A-1$

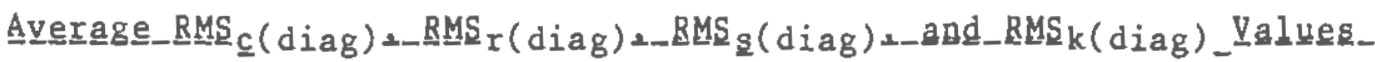

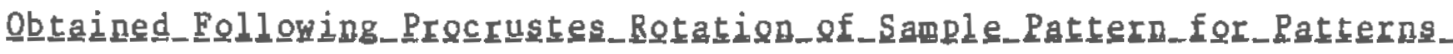

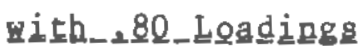

36

72

m

m

RMS $_{i(\mathrm{diag}) \quad \mathrm{N}}$

9

6

9

6

\begin{tabular}{|c|c|c|c|c|c|}
\hline \multirow[t]{5}{*}{$\underline{c}$} & 50 & .0587 & .0472 & * & * \\
\hline & 100 & .0278 & .0201 & .0307 & .0206 \\
\hline & 150 & .0201 & .0124 & .0201 & .0139 \\
\hline & 300 & .0098 & .0067 & .0102 & .0069 \\
\hline & 500 & .0062 & .0040 & .0066 & .0043 \\
\hline \multirow[t]{5}{*}{ I } & 50 & .0627 & .0517 & * & $*$ \\
\hline & 100 & .0293 & .0228 & .0332 & .0231 \\
\hline & 150 & .0212 & .0142 & .0218 & .0160 \\
\hline & 300 & .0108 & .0077 & .0113 & .0079 \\
\hline & 500 & .0068 & .0047 & .0071 & .0046 \\
\hline
\end{tabular}


Table A-1 (continued)

p

36

72

III

m

$\mathbf{R M S}_{\text {i(diag) }}$ N

9

6

9

6

\begin{tabular}{|c|c|c|c|c|c|}
\hline \multirow[t]{5}{*}{$\underline{\underline{g}}$} & 50 & .0355 & .0387 & $\star$ & * \\
\hline & 100 & .0000 & .0000 & .0000 & .0000 \\
\hline & 150 & .0000 & .0000 & .0000 & .0000 \\
\hline & 300 & .0000 & .0000 & .0000 & .0000 \\
\hline & 500 & .0000 & .0000 & .0000 & .0000 \\
\hline \multirow[t]{5}{*}{$\mathrm{k}$} & 50 & .0408 & .0474 & $\star$ & * \\
\hline & 100 & .0000 & .0000 & .0000 & .0000 \\
\hline & 150 & .0000 & .0000 & .0000 & .0000 \\
\hline & 300 & .0000 & .0000 & .0000 & .0000 \\
\hline & 500 & .0000 & .0000 & .0000 & .0000 \\
\hline
\end{tabular}


Table $A-2$

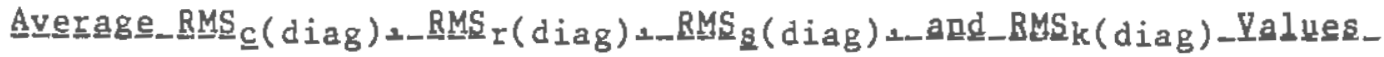
Obtained_Following_Procrugte日_Rotation_of_Sample_Ratterer_for_Eattern_

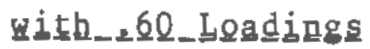

36

72

m

m

$R^{M} S_{i}(\mathrm{diag}) \mathrm{N}$

9

6

9

6

\begin{tabular}{|c|c|c|c|c|c|}
\hline \multirow[t]{5}{*}{$\underline{c}$} & 50 & .1933 & .1395 & * & * \\
\hline & 100 & .0979 & .0546 & .0922 & .0575 \\
\hline & 150 & .0646 & .0389 & .0601 & .0379 \\
\hline & 300 & .0296 & .0197 & .0303 & .0191 \\
\hline & 500 & .0181 & .0116 & .0181 & .0115 \\
\hline \multirow[t]{5}{*}{$I$} & 50 & .2107 & .1614 & * & * \\
\hline & 100 & .1068 & .0631 & .1009 & .0671 \\
\hline & 150 & .0715 & .0451 & .0665 & .0443 \\
\hline & 300 & .0325 & .0233 & .0332 & .0219 \\
\hline & 500 & .0202 & .0138 & .0199 & .0135 \\
\hline
\end{tabular}


Table A-2 (continued)

RMS $_{i}$ (diag) N

9

6

9

6

\begin{tabular}{|c|c|c|c|c|c|}
\hline \multirow[t]{5}{*}{$\underline{s}$} & 50 & .2029 & .1516 & * & * \\
\hline & 100 & .0564 & .0000 & .0234 & .0149 \\
\hline & 150 & .0222 & .0063 & .0039 & .0000 \\
\hline & 300 & .0000 & .0000 & .0000 & .0000 \\
\hline & 500 & .0000 & .0000 & .0000 & .0000 \\
\hline \multirow[t]{5}{*}{$\mathbf{k}$} & 50 & .2369 & .1894 & * & * \\
\hline & 100 & .0647 & .0000 & .0267 & .0181 \\
\hline & 150 & .0254 & .0077 & .0045 & .0000 \\
\hline & 300 & .0000 & .0000 & .0000 & .0000 \\
\hline & 500 & .0000 & .0000 & .0000 & .0000 \\
\hline
\end{tabular}


Table A-3

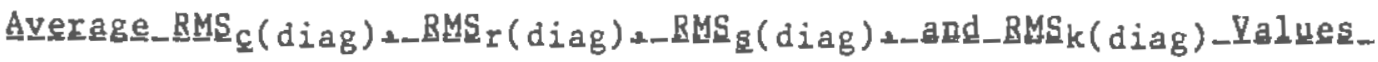

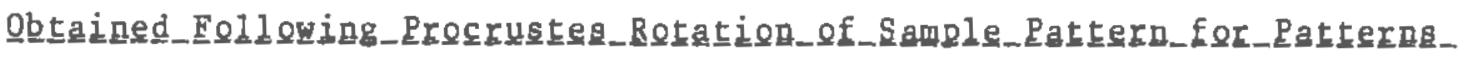

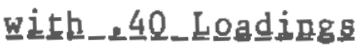

$\operatorname{RMS}_{i}(\mathrm{diag}) \mathrm{N}$

9

6

9

6

\begin{tabular}{|c|c|c|c|c|c|}
\hline \multirow[t]{5}{*}{ c } & 50 & .3965 & .3695 & * & * \\
\hline & 100 & .3156 & .2639 & .3235 & .1682 \\
\hline & 150 & .2447 & .2029 & .2392 & .1243 \\
\hline & 300 & .1661 & .0855 & .1043 & .0652 \\
\hline & 500 & .0919 & .0421 & .0636 & .0399 \\
\hline \multirow[t]{5}{*}{$I$} & 50 & .4177 & .3998 & * & * \\
\hline & 100 & .3373 & .2988 & .3444 & .1914 \\
\hline & 150 & .2586 & .2144 & .2550 & .1418 \\
\hline & 300 & .1773 & .0983 & .1151 & .0753 \\
\hline & 500 & .0994 & .0496 & .0702 & .0467 \\
\hline
\end{tabular}


Table A-3 (continued)

\section{P}

36

72

m

m

$\begin{array}{lllll}\text { RMS }_{i}(\mathrm{~d} \text { iag }) & 9 & 6 & 9\end{array}$

\begin{tabular}{|c|c|c|c|c|c|}
\hline \multirow[t]{5}{*}{$\underline{\mathbf{s}}$} & 50 & .4363 & .4217 & * & * \\
\hline & 100 & .3251 & .2368 & .2744 & .0998 \\
\hline & 150 & .2128 & .1729 & .1477 & .0524 \\
\hline & 300 & .1098 & .0200 & .0045 & .0119 \\
\hline & 500 & .0370 & .0000 & .0000 & .0000 \\
\hline \multirow[t]{5}{*}{$k$} & 50 & .5143 & .5194 & * & * \\
\hline & 100 & .3779 & .2916 & .3118 & .1198 \\
\hline & 150 & .2446 & .2114 & .1662 & .0621 \\
\hline & 300 & .1251 & .0241 & .0049 & .0145 \\
\hline & 500 & .0419 & .0000 & .0000 & .0000 \\
\hline
\end{tabular}


Table A-4

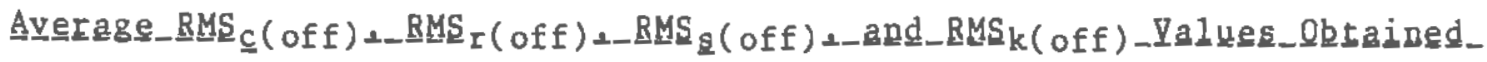

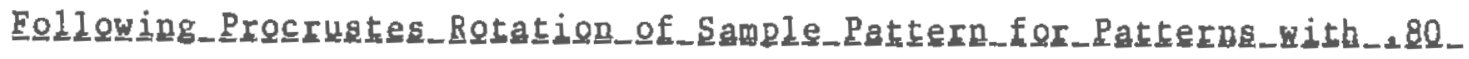

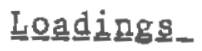

\section{P}

36

72

m

m

RMS $_{i \text { (off) N }}$

9

6

9

6

\begin{tabular}{|c|c|c|c|c|c|}
\hline \multirow[t]{5}{*}{$\mathrm{E}$} & 50 & .0719 & .0856 & $*$ & * \\
\hline & 100 & .0472 & .0494 & .0485 & .0478 \\
\hline & 150 & .0426 & .0359 & .0364 & .0403 \\
\hline & 300 & .0267 & .0294 & .0271 & .0269 \\
\hline & 500 & .0228 & .0220 & .0223 & .0237 \\
\hline \multirow[t]{5}{*}{$\mathbf{r}$} & 50 & .1398 & .2100 & $\star$ & $\star$ \\
\hline & 100 & .1307 & .2030 & .1311 & .2019 \\
\hline & 150 & .1300 & .2010 & .1283 & .2021 \\
\hline & 300 & .1271 & .2013 & .1270 & .2006 \\
\hline & 500 & .1266 & .2006 & .1263 & .2005 \\
\hline
\end{tabular}


Table A-4 (continued)

p

36

72

요

$\mathbf{m}$

$\begin{array}{llllll}\text { RMS }_{i} \text { (OfF) } & N & 9 & 6 & 9 & 6\end{array}$

\begin{tabular}{|c|c|c|c|c|c|}
\hline \multirow[t]{5}{*}{$\underline{B}$} & 50 & .0223 & .0324 & $\star$ & * \\
\hline & 100 & .0000 & .0000 & .0000 & .0000 \\
\hline & 150 & .0000 & .0000 & .0000 & .0000 \\
\hline & 300 & .0000 & .0000 & .0000 & .0000 \\
\hline & 500 & .0000 & .0000 & .0000 & .0000 \\
\hline \multirow[t]{5}{*}{$\mathrm{k}$} & 50 & .0106 & .0000 & * & * \\
\hline & 100 & .0000 & .0000 & .0000 & .0000 \\
\hline & 150 & .0000 & .0000 & .0000 & .0000 \\
\hline & 300 & .0000 & .0000 & .0000 & .0000 \\
\hline & 500 & .0000 & .0000 & .0000 & .0000 \\
\hline
\end{tabular}


Table A-5

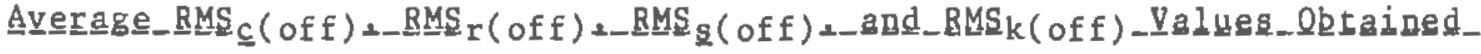

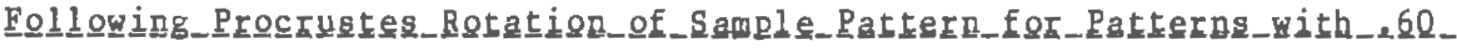

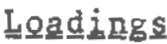

P

36

72

m

m

$R M 5_{i}$ (of $f$ ) N

9

6

9

6

c

50

.0852

.0887

*

*

100

.0558

.0455

.0551

.0492

150

.0443

.0351

.0376

.0401

300

.0294

.0291

.0285

.0295

500

.0201

.0247

.0231

.0219

I

50
100
150
300

.1339

.1936

*

*

100

.1269

.1941

.1270

.1944

150

.1255

.1950

.1235

.1959

500

.1249

.1980

.1245

.1979

.1244

.1993

.1249

.1989 
Table A-5 (continued)

P

36

72

II

m

RMS $_{i}$ (off) N

9

6

9

6

\begin{tabular}{|c|c|c|c|c|c|}
\hline \multirow[t]{5}{*}{$\underline{\mathrm{s}}$} & 50 & .0841 & .0794 & * & * \\
\hline & 100 & .0399 & .0000 & .0153 & .0119 \\
\hline & 150 & .0157 & .0056 & .0028 & .0000 \\
\hline & 300 & .0000 & .0000 & .0000 & .0000 \\
\hline & 500 & .0000 & .0000 & .0000 & .0000 \\
\hline \multirow[t]{5}{*}{$\mathbf{k}$} & 50 & .0441 & .0136 & * & * \\
\hline & 100 & .0225 & .0000 & .0000 & .0000 \\
\hline & 150 & .0079 & .0000 & .0000 & .0000 \\
\hline & 300 & .0000 & .0000 & .0000 & .0000 \\
\hline & 500 & .0000 & .0000 & .0000 & .0000 \\
\hline
\end{tabular}


Table A-6

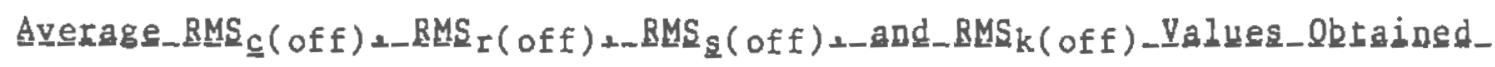

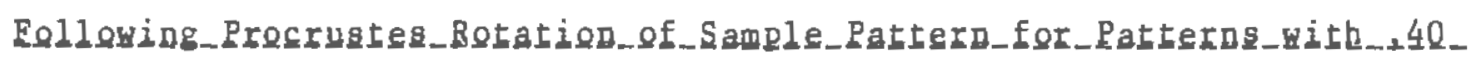
Leadings

36

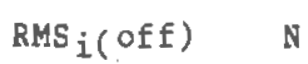

9

6

9

6

\begin{tabular}{|c|c|c|c|c|c|}
\hline \multirow[t]{5}{*}{ c } & 50 & .0999 & .1008 & * & * \\
\hline & 100 & .0959 & .0788 & .0829 & .0536 \\
\hline & 150 & .0739 & .0911 & .0682 & .0480 \\
\hline & 300 & .0663 & .0358 & .0325 & .0261 \\
\hline & 500 & .0377 & .0261 & .0231 & .0194 \\
\hline \multirow[t]{5}{*}{$\mathbf{r}$} & 50 & .1265 & .1605 & * & * \\
\hline & 100 & .1308 & .1716 & .1199 & .1732 \\
\hline & 150 & .1212 & .1831 & .1189 & .1790 \\
\hline & 300 & .1266 & .1853 & .1160 & .1870 \\
\hline & 500 & .1198 & .1924 & .1189 & .1918 \\
\hline
\end{tabular}

